Research Article

\title{
Effect of CFRP Shear Strengthening on the Flexural Performance of the RC Specimen under Unequal Impact Loading
}

\author{
Yanhui Liu (D), Khalil Al-Bukhaiti $(\mathbb{D}$, Hussein Abas, and Zhao Shichun \\ School of Civil Engineering, Southwest Jiaotong University, Chengdu 610031, China \\ Correspondence should be addressed to Khalil Al-Bukhaiti; eng.khalil670@gmail.com
}

Received 18 May 2020; Revised 18 October 2020; Accepted 31 October 2020; Published 18 November 2020

Academic Editor: Giorgio Pia

Copyright (C) 2020 Yanhui Liu et al. This is an open access article distributed under the Creative Commons Attribution License, which permits unrestricted use, distribution, and reproduction in any medium, provided the original work is properly cited.

\begin{abstract}
Strengthening with externally bonded CFRP reinforcement is widely used in structural reinforcement and attractive to stakeholders and engineers because of ease and speed of construction, corrosion resistance, lightweight, high strength, and versatility stiffness which can be oriented according to the need. Numerous research studies were carried out to explore RC beams' flexural and shear performance when subjected to dynamic impact loading. The results were auspicious in using such a technique of strengthening. Regular square section reinforced concrete frame members strengthened by CFRP material is taken as the research object. However, little attention to the impact behavior of CFRP-shear-strengthened square reinforced concrete (RC) specimens has been paid. The dynamic response of CFRP to reinforced concrete members under unequal cross-impact is discussed. This paper investigates the effectiveness of CFRP strengthening on the square RC specimen in preventing shear failure and evaluation of the flexural performance of the strengthened specimen under the impact load. The drop hammer impact test is firstly conducted on RC specimens with and without CFRP strengthening. The results show that using CFRP to strengthen the RC specimen in shear is very effective at preventing shear failure and leading the specimen's response to flexural domination. This result is also the motivation for developing a numerical model supported by experimental tests to study the flexural performance of strengthened RC specimens. It is found that the strengthened specimen is prone to exhibit pure bending deformation under the impact load in terms of dynamic amplification factor (DAF) for section moment. Then, an extensive parameter study is carried out to evaluate further the influence of impact velocity, reinforcement ratio, and concrete strength on the flexural performance of the strengthened specimen and CFRP layers. Such a holistic study may provide preliminary research regarding the use of CFRP to strengthen RC specimens in shear under impact loads and will enhance the current state of knowledge in this area; also, the optimal value of the CFRP reinforcement layer was proposed.
\end{abstract}

\section{Introduction}

Due to the demand in the engineering construction field, FRP was introduced in the 1980 s to enhance the tensile and compressive strength of materials employed in this field, which promotes more efficient, safe, stable, environmentally friendly, and strong structures. Fiber composite materials such as carbon fibers have been utilized in many applications and transformed to this construction field throughout the life cycles of the RC structures considering the late 1980s [1]. Impact loads can lead to considerable responses to structures in an instant duration. The previous literature by Niu et al. [2-5] reported that those RC beams or columns are exhibiting bending failure under static load and were more likely to show shear failures under high loading rate. It is known that shear failure of concrete structures is usually catastrophic and brittle compared with flexural failure; once it happened, it is very likely to lead to dire consequences. In contrast, the flexural failure is ductile and thus more acceptable in civil engineering constructions. Therefore, it is necessary to avoid shear failure of RC members, which are likely to subject to impact loads and lead them to be governed by flexural responses; an effective method is needed to increase the shear capacity of RC structures.

Fiber-reinforced polymer (FRP) has received increased attention in the last decades because of its low mass density, high ultimate tensile strength, and good corrosion resistance. Externally wrapping FRP sheets on concrete 
components can improve their strength, stiffness, and ductility. Recent studies have investigated the availabilities of FRP in strengthening concrete components in flexure under impact loads and confining concrete columns to improve their axial dynamic resistance as well. Almost all the studies indicate that it is very promising to utilize FRP sheets in strengthening concrete components. However, very limited literature investigates the dynamic response of FRP-shear-strengthened RC specimens under impact loads (Soleimani et al.) [6-9]. Shafei and Kabir carried out a drop-hammer test on shear-strengthened RC beams with two kinds of FRP sheets, that is, unidirectional fiber and cross-fiber FRP [7]. The results show that both FRP sheets can reduce the deflection of the members, restrain the development of shear cracks, reduce the degree of damage, and increase the energy absorption capacity of the members. Pham and Hao studied the mechanical properties of RC beams strengthened with FRP under impact [8]. Considering U-shaped and 45-degree inclined wrapping schemes, 13 RC beams without stirrups were tested. The test results show that the RC beams strengthened with FRP have a remarkable increase in bearing capacity, indicating that FRP increases the stiffness of the beams. The 45-degree oblique wrapping is more effective than U-type wrapping in improving the bearing capacity and controlling the deflection of the beams. In recent work, Liu and Xiao have also carried out drop-weight impact tests on shearstrengthened RC beams to study the shear failure behavior and the strengthening effect of CFRP [9]. The effects of different impact velocities and energy on the dynamic response of beams have been discussed. It is found that the $\mathrm{RC}$ beams with insufficient shear strength can be effectively strengthened by wrapping all the CFRP around the beams, and the shear failure of the test members can be effectively prevented by increasing the reinforcement ratio of CFRP. When the impact energy is increased, the bending failure of the RC beams will occur, and severe local failure will develop at the impact region as well.

The above studies indicate that the strengthened RC components have a higher shear capacity and less shear damage compared with unstrengthened components. Those strengthened components are thus expected to experience ductile flexural mechanisms under impact loads. However, the research work on the flexural performance of CFRPshear-strengthened RC components has still lacked. In the present study, the drop hammer impact test on CFRP-shearstrengthened and unstrengthened $\mathrm{RC}$ specimens $\mathrm{FH} 2$ are firstly carried out. The primary object of the test is to investigate the impact behavior of CFRP-shear-strengthened RC specimen FH2-H1. To better examine the strengthening effect of CFRP, unlike the midspan impact in the majority of previous studies, the impact position in the current study is set at the (2/9) length of the effective span to promote the occurrence of shear failure for the specimens. Numerical models are also developed and calibrated with experimental results. With the calibrated models, the flexural performance of tested specimens is discussed, and an extensive parametric study is conducted. The effectiveness of impact velocity to impact and lateral deflection, reinforcement ratio, concrete strength on the flexural performance of the strengthened specimen, and CFRP layers is examined.

\section{Materials and Methods}

2.1. Specimen Preparation. A total of two RC specimens, including one unstrengthened RC specimen, which was served as the control specimen FH2, and one CFRP-shearstrengthened RC specimen $\mathrm{FH} 2-\mathrm{H} 1$, were prepared. The detailed configuration of the specimen is shown in Figure 1. The specimens have a total length of $1500 \mathrm{~mm}$ with a cross section of $120 * 120 \mathrm{~mm}$ and a cover of $20 \mathrm{~mm}$; four longitudinal reinforcement bars with a diameter of $8 \mathrm{~mm}$ were arranged around the circumference of the cross section with a reinforcement ratio of $2 \%$. Also, a certain number of $4 \mathrm{~mm}$ stirrups with an interval of $50 \mathrm{~mm}$ were arranged along the length of the specimen. The strengthened specimen was made using the wet layup technique. The epoxy adhesive was used to achieve bonding between CFRP and concrete. Figure 2(a) shows the diagram of the strengthening process; the RC specimen was wrapped continuously along the span with a certain number of CFRP strips (width of $200 \mathrm{~mm}$ for each strip), and it was also wholly wrapped in hoop direction with a hoop overlap of $120 \mathrm{~mm}$, in case of the debonding failure during the impact.

2.2. Material Properties. The static tensile test was carried out to measure the material properties of steel coupons, which were cut from the same batch installed in the specimen. The mass density and Young's modulus for longitudinal and stirrups reinforcement were $7800 \mathrm{~kg} / \mathrm{m}^{3}$ and $210 \mathrm{GPa}$, respectively. Ultimate strength for longitudinal and stirrups reinforcement was $320 \mathrm{MPa}$ and $520 \mathrm{MPa}$, respectively, and the tensile test of steel bars, as shown in Figure 3(a). The compressive test was performed on $150 \mathrm{~mm} * 150 \mathrm{~mm} * 150 \mathrm{~mm}$ concrete cubes, as shown in Figure 3(b). The average measured the strength of concrete cubes at 28 days was $43.5 \mathrm{MPa}$. The unidirectional carbon fiber reinforced polymer (CFRP) material used in this study was supplied by Torayca Inc. [10]. The CFRP sheet was commercially known as UT70-30G [11]. The density and thickness of CFRP sheets were provided by the supplier. Furthermore, the other material properties of epoxy-cured CFRP, such as tensile strength and Young's modulus, were obtained through tensile coupon tests. The epoxy adhesive used in the test was Araldite XH 180. As CFRP is an orthotropic material, the in-plane shear properties and the properties of in-plan principal directions (i.e., longitudinal and transverse direction in the plane, respectively) were tested by the specifications of ASTM D3039-08 [12]. The test of different CFRP coupons is shown in Figures 3(c)-3(e). The detailed material properties are given in Table 1 .

2.3. Test Setup and Procedure. Figure 1 shows the schematic view of the experimental setup. Dynamic impact tests are conducted based on a drop test system (DHR-9401) at the Taiyuan University of Technology, China. The specimen was placed on two supports at each end. The support was 


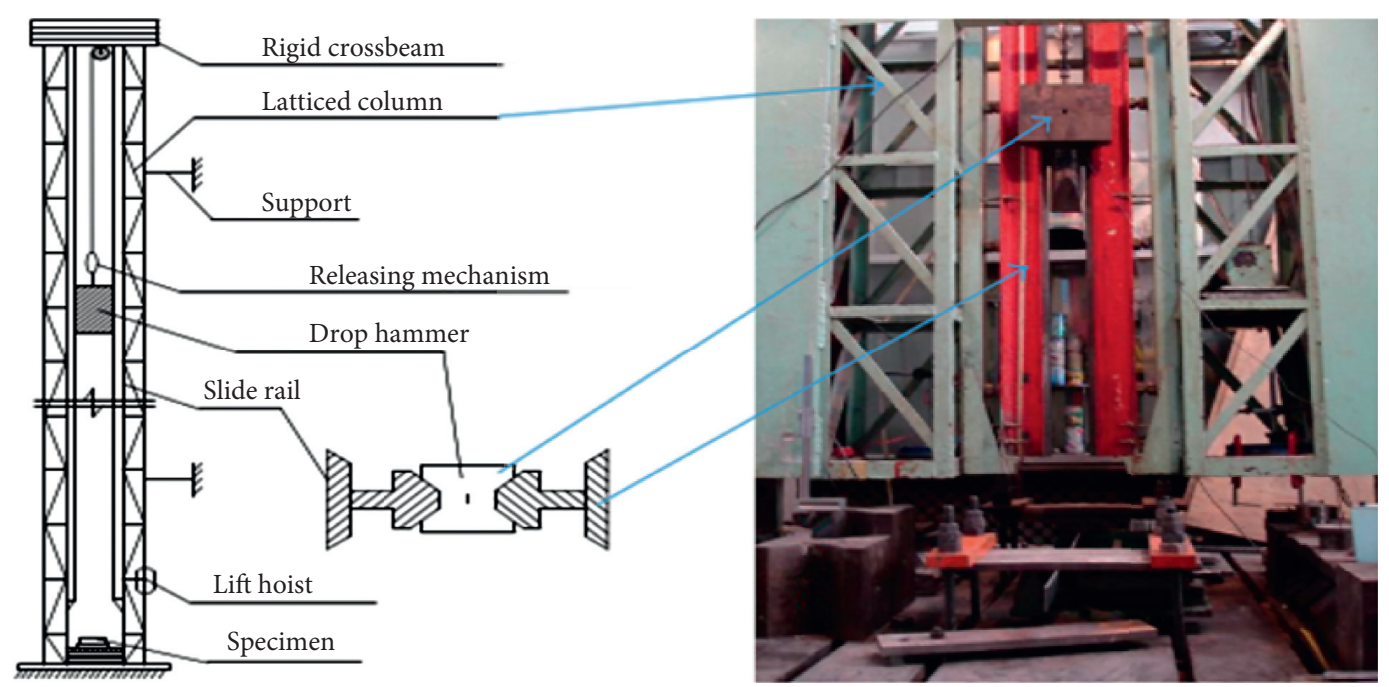

(a)
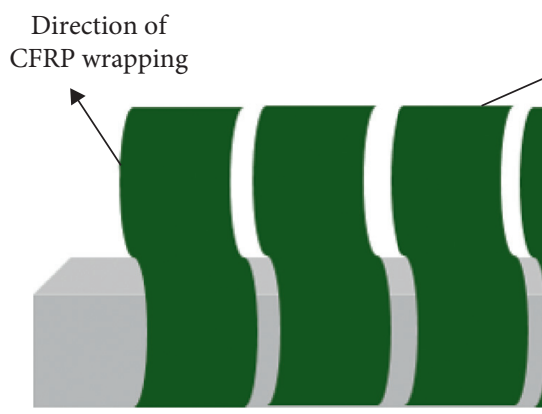

CFRP laminates

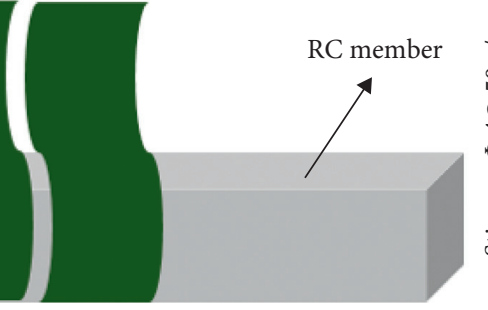

(b)

Figure 1: (a) DHR9401 drop hammer test machine. (b) Schematic view of test setup (mm).

composed of high-strength steel clamps. As can be seen in Figure 1, the length of each support was $200 \mathrm{~mm}$. Thus, the length of the effective span of the specimen was $900 \mathrm{~mm}$. The impact position was set at the $2 / 9$ span of the effective length, that is, $200 \mathrm{~mm}$ away from the right support and $700 \mathrm{~mm}$ away from the left support, to promote the occurrence of shear failure of the RC specimen. The drop distance between the bottom surface of the drop hammer and the top surface of the specimen was set to $2000 \mathrm{~mm}$ for obtaining the initial impact velocity of $6.26 \mathrm{~m} / \mathrm{s}$. The total mass of the drop hammer was set as $270 \mathrm{~kg}$, consisting of a falling weight, load cell, and impactor with a $30 \mathrm{~mm} * 80 \mathrm{~mm}$ rectangular face as shown in Figure 2(b); the load cell was set between the impactor and falling weight to record the impact force. Moreover, to capture the crack propagation during the impact, a high-speed camera was installed in front of the impact area with a shooting speed of 2500 frames/second. These types of equipment are used to record the evolution of the failure mechanisms and to digitize the data, respectively.

\section{Results and Discussion}

3.1. Crack Propagation and Failure Modes. Figure 4 depicts the crack propagation of the tested specimens. Arrows were added in pictures to indicate the tiny cracks that were difficult to be observed during the impact. For the unstrengthened specimen (Figure 4(a)), several diagonal shear cracks were found originating at the impact point in a concise duration after the contact between the impactor and specimen $(0.4 \mathrm{~ms})$. In the meanwhile, a vertical crack was detected at the bottom of the impact section as well. Subsequently, at $4.0 \mathrm{~ms}$, the diagonal cracks were more pronounced. They became wider and propagated downward with an angle of approximately $45^{\circ}$ from the impact point to the bottom of the right support section. In contrast, the development of vertical cracks was relatively insignificant. Then, it was found that the diagonal shear cracks had split concrete into several parts at the time of $4.0 \mathrm{~ms}$, while for the CFRP-shear-strengthened specimen, at the very early stage $(0.4 \mathrm{~ms})$, vertical cracks were observed at the bottom of the impact section, as shown in Figure 4(b). Subsequently, it can be seen clearly that the prominent vertical cracks on both CFRP and concrete at the impact section became wider and developed upward through the height of the section, indicating the vertical flexural cracks had dominated the failure of the CFRP-shear-strengthened specimen. It should be noted that although the crack propagation on concrete could not be observed clearly in the initial stage of the impact due to the wrap of CFRP. Nevertheless, according to the observation described in the later paragraph, no debonding failure was found on the vertical crack region. Therefore, it 


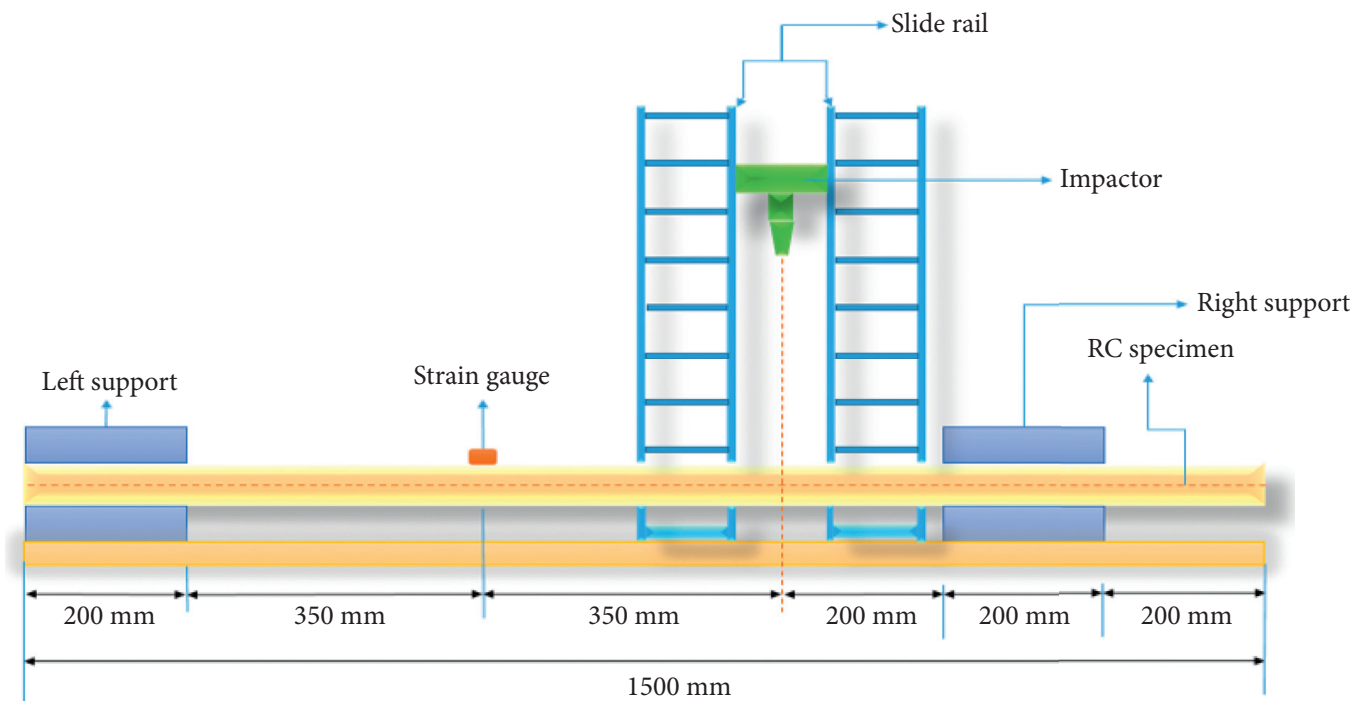

(a)
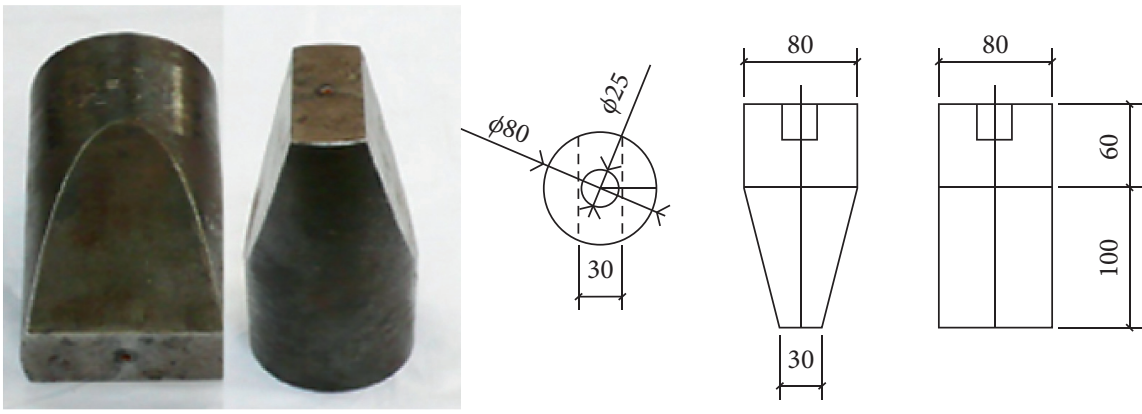

(b)

Figure 2: (a) Diagram of the strengthening process. (b) Details of the drop hammer.

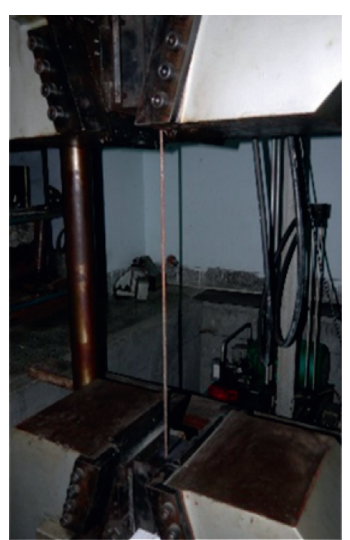

(a)

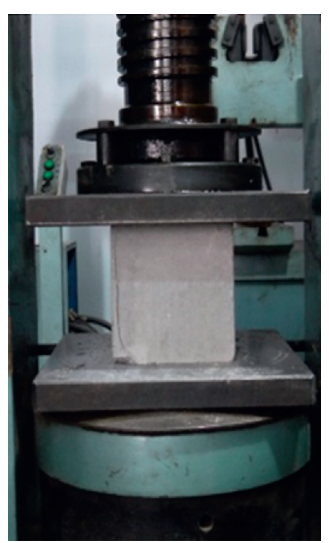

(b)

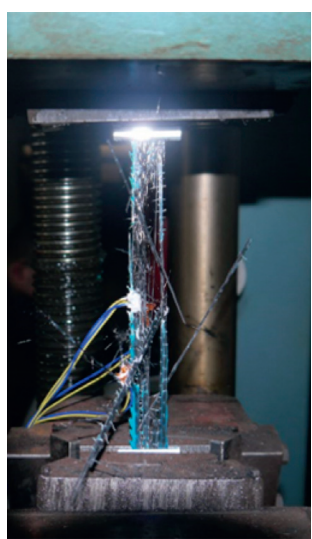

(c)

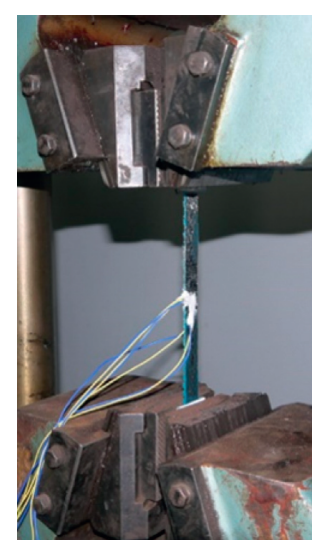

(d)

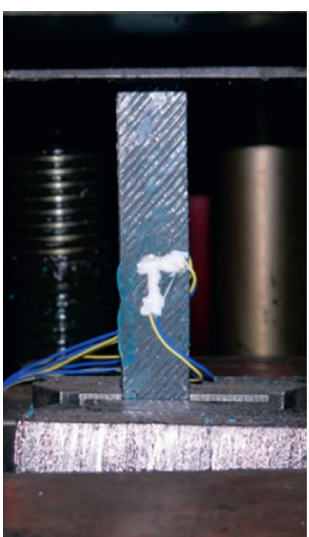

(e)

Figure 3: Tested materials coupons. (a) Steel bar tensile test. (b) Cube uniaxial compression. (c) Longitudinal direction. (d) Transverse direction. (e) In-plane shear.

was reasonable to assume the cracks observed on CFRP occur simultaneously on concrete in the same region.

Figure 5 shows the failure modes of the tested specimens after impact. It can be seen that, for the $\mathrm{FH} 2$ specimen, as shown in (Figure 5(a)), massive spalling of concrete with the failure of the steel reinforcement bars was observed in the diagonal crack region. Additionally, vertical flexural cracks were also observed at the top of the left support section, 
TABLE 1: The details of material properties.

\begin{tabular}{lcr}
\hline Material & Parameter & Magnitude \\
\hline & Mass density & $7800 \mathrm{~kg} / \mathrm{m}^{3}$ \\
Steel & Young's modulus & $210 \mathrm{GPa}$ \\
& $320 \mathrm{MPa}$ & $520 \mathrm{MPa}$ \\
\hline Concrete & Ultimate longitudinal strength & $43.5 \mathrm{MPa}$ \\
\hline & Ultimate stirrups strength & $3960 \mathrm{MPa}$ \\
& Compressive strength & $205 \mathrm{GPa}$ \\
FRP & Longitudinal tensile strength & $74 \mathrm{MPa}$ \\
& Longitudinal Young's modulus & $18 \mathrm{GPa}$ \\
& Transverse tensile strength & $108 \mathrm{MPa}$ \\
& Transverse Young's modulus & $47 \mathrm{GPa}$ \\
\hline
\end{tabular}
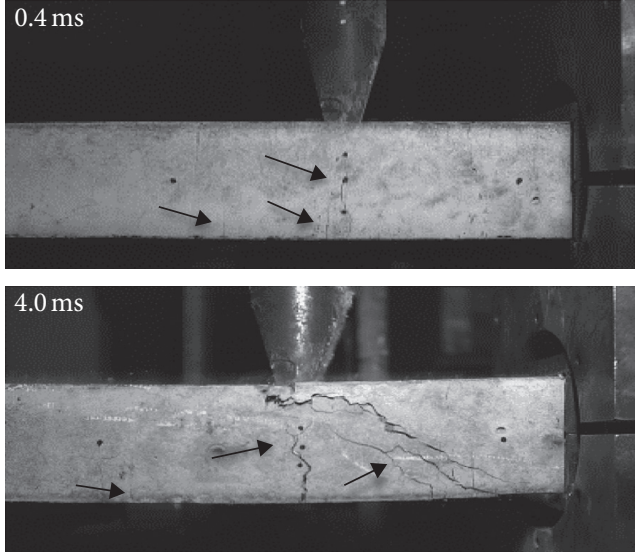

(a)
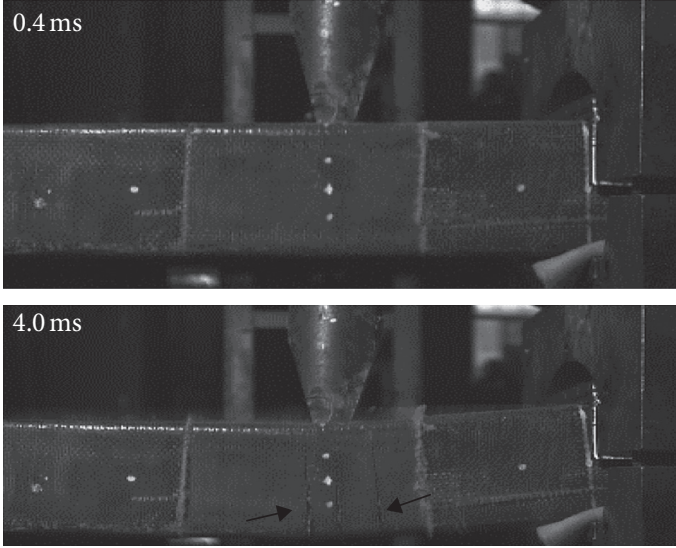

(b)

FIGURE 4: Crack propagation. (a) Unstrengthened specimen. (b) CFRP-shear-strengthened specimen.

while, for the CFRP-shear-strengthened specimen, as illustrated in (Figure 5(b)), prominent vertical cracks were detected at the impact section and the right support section with the fracture of longitudinal steel bars. Compared with the main vertical crack on the impact section and right support section, also prominent vertical cracks were found at the top of the left support section of the $\mathrm{FH} 2-\mathrm{H} 1$ with the fracture of longitudinal steel bars. The results revealed that the shear capacity of the strengthened RC specimen was significantly larger than its flexural capacity, leading to a flexural failure mode occurred during the impact. In addition, the vertical flexural cracks on the impact section, and two support sections indicated these regions had exceeded an ultimate section bending moment during the impact. It also should be noted that no debonding could be observed between CFRP and concrete, even on the crack area, as illustrated in Figure 5(b), so the CFRP and concrete could work together under the impact load.

The above observations showed that CFRP strengthening could transform the failure mechanism of RC specimen from shear failure mode to flexural failure mode and thus could effectively prevent the appearance of shear failure.
3.2. Time History Curves of Impact Force. Figure 6 presents the time history curves of impact force recorded in the test. The time axis starts from the moment when the impactor contacts the specimen. It can be seen that, at the onset of the impact, two curves of $\mathrm{FH} 2$ and $\mathrm{FH} 2-\mathrm{H} 1$ exhibited similar shapes. Both increased sharply to their peak value $(493 \mathrm{kN}$ and $504 \mathrm{kN}$, respectively) in an instant duration (about $6.0 \mathrm{~ms}$ and $0.8 \mathrm{~ms}$, respectively), similar to other impact tests $[13,14]$. Soon after, the force dropped immediately with a short period of severe fluctuation and reached a relatively stable level. The impact force at this stage is usually defined as the plateau phase, where the lateral resistance of the specimen plays a vital role in resisting impact load. As shown in Figure 6(a), the force of the unstrengthened specimen during the plateau phase remained at a lower level $(45 \sim 65 \mathrm{kN})$ until $40 \mathrm{~ms}$ when the force started to unload. By contrast, the force of the strengthened specimen was significantly larger at the early stage of the plateau phase; it climbed to $155 \mathrm{kN}$ at the time of $4.5 \mathrm{~ms}$. Right after that, however, a sudden drop was observed from $150 \mathrm{kN}$ to $30 \mathrm{kN}$ at $6.0 \mathrm{~ms}$. This is due to the fact that the fracture of the longitudinal reinforcement bars at the time of $6.0 \mathrm{~ms}$ caused 

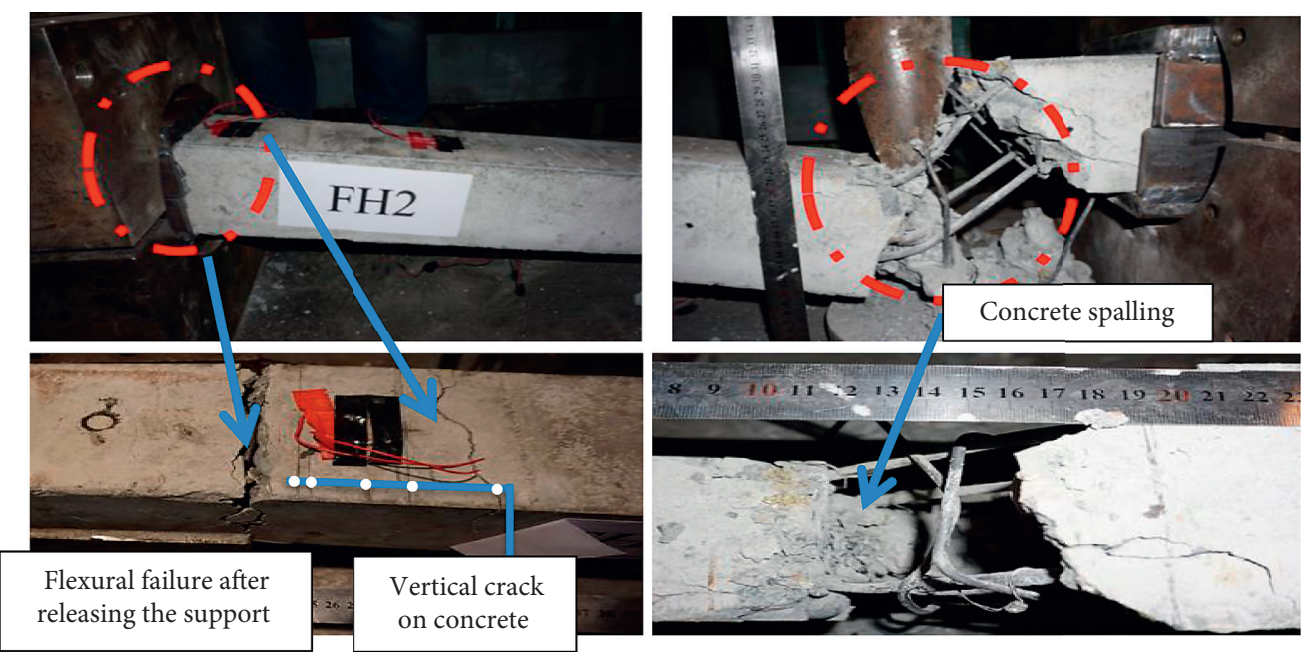

(a)

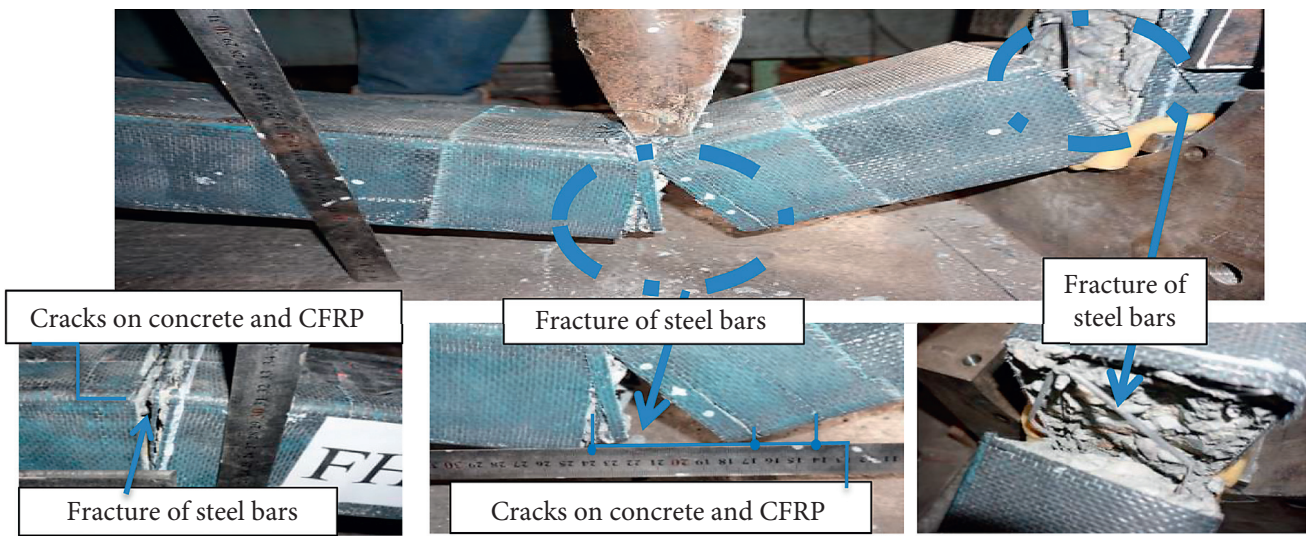

(b)

FIGURE 5: Failure modes for specimens after impact. (a) FH2 Unstrengthened specimen. (b) FH2-H1 CFRP-shear-strengthened specimen.

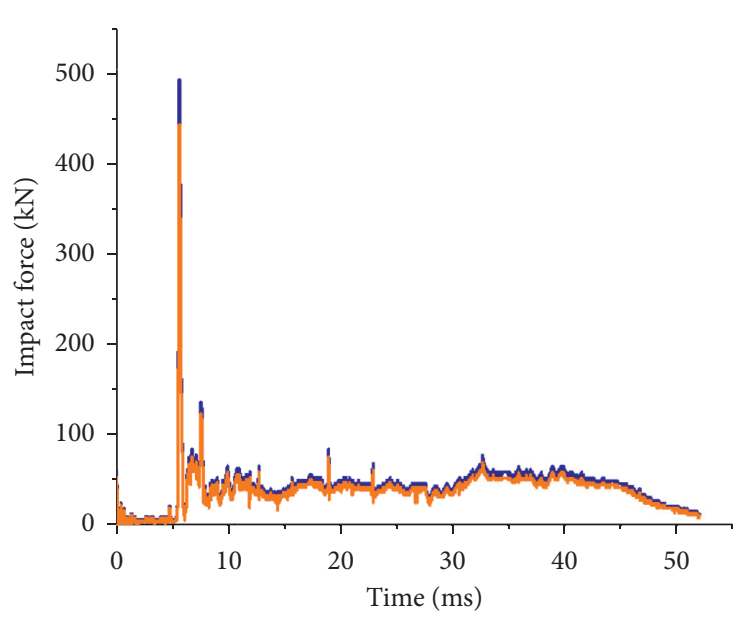

FH2

Exp

FE

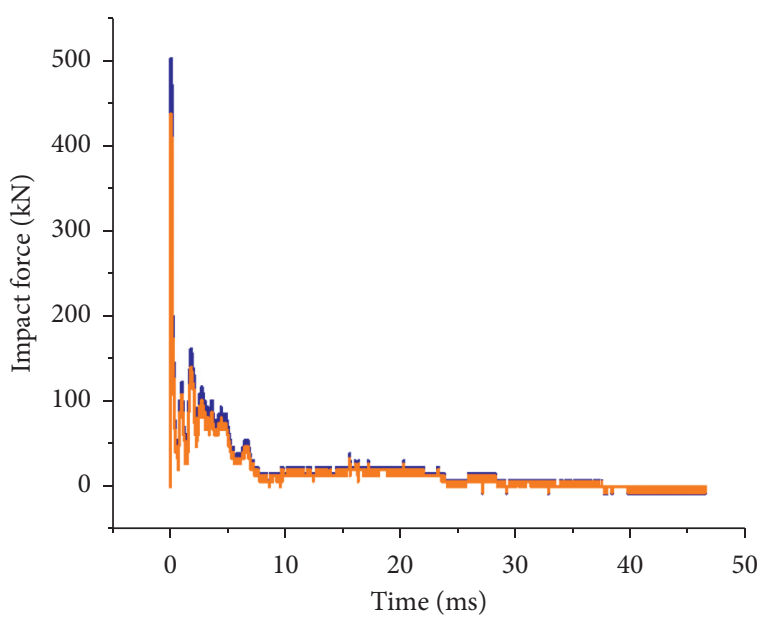

FH2-H1

- Exp

(a)

(b)

FIGURE 6: Time history curves of the impact force. (a) Unstrengthened specimen. (b) CFRP-shear-strengthened specimen. 
the specimen to lose lateral resistance immediately. With lower resistance, the strengthened specimen ended up with a shorter impact duration compared with the unstrengthened one (53 ms versus $38 \mathrm{~ms}$ ). Strictly speaking, this is due to the rapid decrease in lateral rigidity.

3.3. Numerical Model Development. Compared with experimental tests, using the numerical simulation method is useful in saving time and money on further investigations on the dynamic response of CFRP-shear-strengthened RC specimens. However, it is complex to model the response of RC specimens strengthened by CFRP with much nonlinear behavior such as including cracks, spalling of concrete, and fracture of steel bars. For this reason, the research on the dynamic responses of CFRP-shear-strengthened RC specimens is limited. In this section, a numerical simulation carries out uses an explicit finite element (FE) software ABAQUS, which can provide various contact definitions and material models and has been widely applied in analyzing the structure's response to impact blast loads.

3.4. Element Types and Geometry. Figure 7 illustrates the numerical model of the RC specimen under the impact. The ordinary steel bar is simulated by the linear truss element (T3D2). The three-dimensional truss element is only stressed in the axial direction but not in the tangential direction, whereas the other parts in the model are all threedimensional solid units. Three-dimensional linear reduction integration unit (C3D8R) element type is used for the concrete block. The slip is the displacement difference between the first (reference point) RP1 point on the hammer and the second (reference point) RP2 on a concrete block. The support conditions of components are assigned to keep it consistent with the experimental tests. Both ends of the components are fixed by introducing a reference point at the support section. This unit has one integration point in each direction compared to the complete integration unit, so the calculation efficiency is high. The types of elements available in the ABAQUS library are capable of adopting reduced integration and overcoming hourglass numerical problems. The mode in which the unit is in zero energy when bending and the effect of the hourglass can be eliminated by the algorithm of the enhanced hourglass control, and the subdivision grid is used to eliminate the influence of the calculation accuracy and the unit suitable for contact problems under large strains. The layers are also modeled to consider the frictional effect, as observed in the experiment part.

3.5. Material Model. Dynamic transverse impact simulation is conducted using ABAQUS/Explicit (SIMULIA, 2017) software package [15]. Initially, the dynamic response of the CFRP-shear-strengthened RC specimen has been modeled and analyzed. The results are compared with the drop hammer impact test conducted by the experimental of the model specimens; in order to simulate the behavior of the impact force that was an effect on RC, members were reinforced by CFRP as shown in Figure 1(b) to ensure that the numerical modeling and analysis process are accurate. In ABAQUS 2017/Explicit [16], previous literature has shown that this material model can reasonably predict the dynamic behavior of concrete under the impact and blast load [17-19]. The compressive strength was taken to 43.5 MPa based on the material test mentioned in Section 2. Moreover, the mesh of the element should be refined appropriately according to the requirement. The particular mesh division appears in (Figure $7(\mathrm{~b})$ ). The contact characteristics for the whole gathering must be deliberately characterized and input, including all surfaces and interactions, to simulate an exact reaction from the carbon fiber. This simulation was practiced utilizing ABAQUS 2017/ Explicit with contact pair definition since this explicit method takes into account surface-to-surface enforcement of the contact without iteration. The material properties used in FE models are given in Table 1. The mass density and Young's modulus for longitudinal and stirrups reinforcement were $7800 \mathrm{~kg} / \mathrm{m}^{3}$ and $210 \mathrm{GPa}$, respectively. Ultimate strength for longitudinal and stirrups reinforcement was $320 \mathrm{MPa}$ and $520 \mathrm{MPa}$, respectively. Additionally, the ordinary steel bar is simulated by the linear truss element (T3D2). The three-dimensional truss element is only stressed in the axial direction but not in the tangential direction, whereas the other parts in the model are all threedimensional solid units. Three-dimensional linear reduction integration unit (C3D8R) element type is used for the concrete block; the slip is the displacement difference between the first (reference point) RP1 point on the hammer and the second RP2 point on a concrete block. The support conditions of components are assigned to keep it consistent with the experimental tests. Both ends of the components are fixed by introducing a reference point at the support section. This unit has one integration point in each direction than the complete integration unit, so the calculation efficiency is high and the types of element available in ABAQUS library are capable of adopting reduced integration and overcoming hourglass numerical problem. The mode in which the unit is in zero energy when bending and the effect of the hourglass can be eliminated by the algorithm of the enhanced hourglass control, and the subdivision grid is used to eliminate the influence of the calculation accuracy and the unit suitable for contact problems under large strains. The layers are also modeled to consider the frictional effect, as observed in the experiment part.

3.6. Strain Rate Effect. Both the concrete and steel have a high sensitivity in strain rate effect under impact load, and the strength of the materials is enhanced at a higher strain rate. Therefore, it is necessary to consider the strain rate effect of concrete and steel in numerical simulation to obtain reliable results. Typically, the strength increment can be defined by the dynamic increase factor (DIF) for tensile and compressive strength at a given strain rate. In this study, the DIF for compressive strength of concrete is obtained from the code by Comite Euro-International du Beton (CEB) $[20,21]$, as follows: 


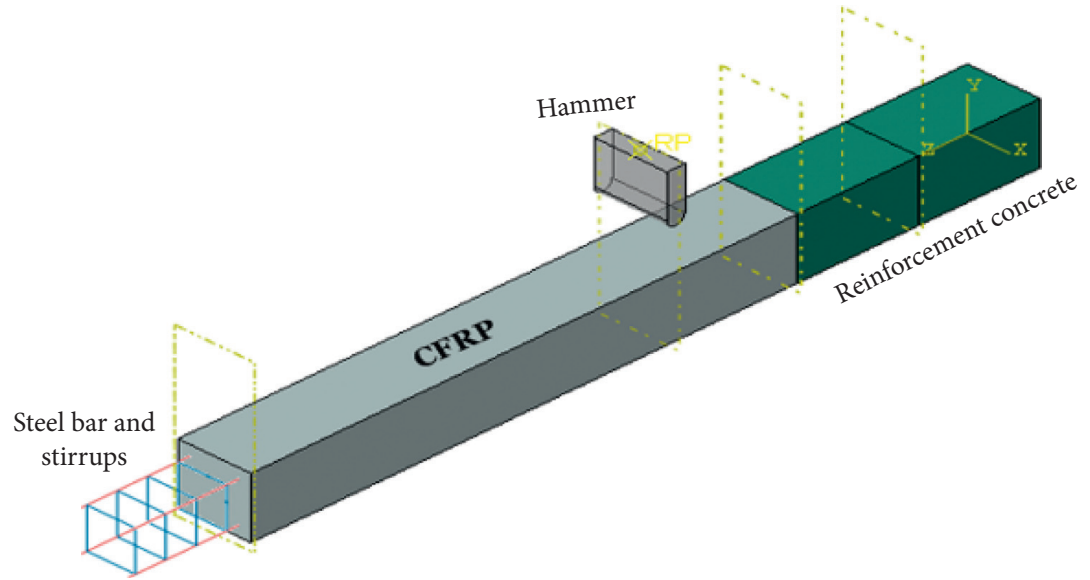

(a)

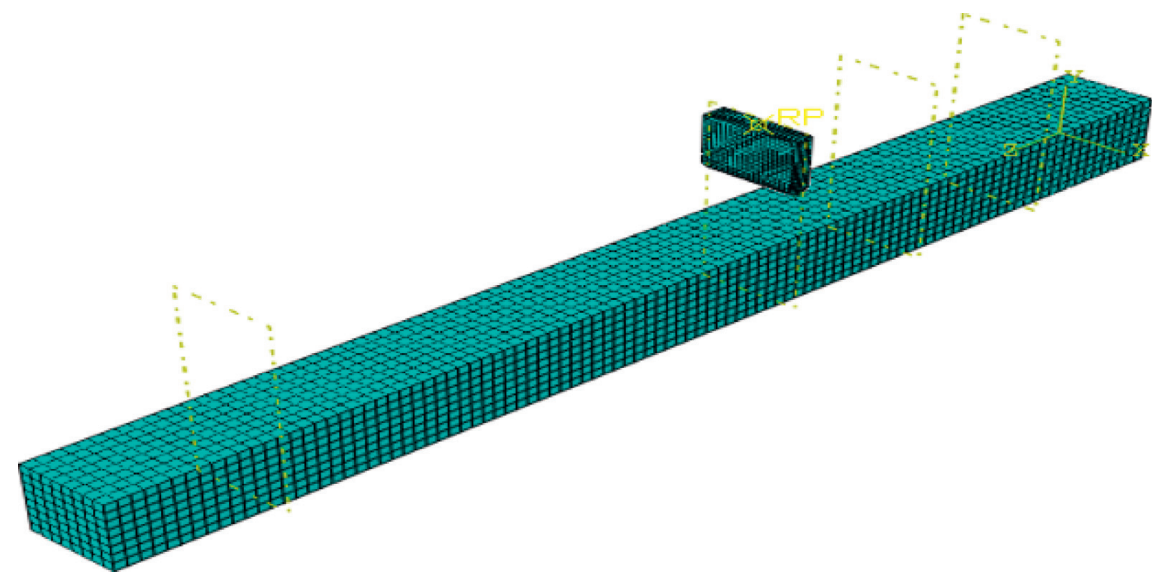

(b)

Figure 7: (a) Simplified numerical modeling. (b) Finite element meshing.

$$
\mathrm{CDIF}=\frac{f_{\mathrm{cd}}}{f_{\mathrm{cs}}}= \begin{cases}\left(\frac{\dot{\varepsilon}_{d}}{\dot{\varepsilon}_{s}}\right)^{1.026 \alpha}, & \dot{\varepsilon}_{d} \leq 30 \mathrm{~s}^{-1}, \\ \gamma\left(\dot{\varepsilon}_{d}\right)^{1 / 3}, & \dot{\varepsilon}_{d}>30 \mathrm{~s}^{-1},\end{cases}
$$

where $f_{\mathrm{cd}}$ and $f_{\mathrm{cs}}$ are the dynamic and static compressive strength at a strain rate $\dot{\varepsilon}_{d}, \dot{\varepsilon}_{s}=30 \times 10^{-6} \mathrm{~s}^{-1}$ (static strain rate) respectively, $\log \gamma=6.156 \alpha-0.49, \alpha=\left(5+3\left(f_{\mathrm{cu}} / 4\right)\right)^{-1}$, and $f_{\mathrm{cu}}$ is the static cube compressive strength (in $\mathrm{MPa}$ ) [20].

The TDIF for concrete in tensile is defined by Malvar and Ross [22], as follows:

$$
\mathrm{TDIF}=\frac{f_{\mathrm{td}}}{f_{\mathrm{ts}}}= \begin{cases}\left(\frac{\dot{\varepsilon}_{d}}{\dot{\varepsilon}_{s}}\right)^{\delta}, & \dot{\varepsilon}_{d} \leq 1 \mathrm{~s}^{-1}, \\ \beta\left(\frac{\dot{\varepsilon}_{d}}{\dot{\varepsilon}_{s}}\right)^{1 / 3}, & \dot{\varepsilon}_{d}>1 \mathrm{~s}^{-1},\end{cases}
$$

where $f_{\text {td }}$ and $f_{\text {ts }}$ are, respectively, the dynamic uniaxial tensile strength at the strain rate $\dot{\varepsilon}_{d}$ and the quasi-static uniaxial tensile strength, $\dot{\varepsilon}_{s}=10^{-6} \mathrm{~s}^{-1}$ (the static strain rate), $\log \beta=6 \delta-2, \delta=\left(1+\left(8 f_{c}^{\prime} / f_{c o}^{\prime}\right)\right)^{-1}, f_{c o}^{\prime}=10 \mathrm{MPa}$, and $f_{c}^{\prime}$ is the quasi-static uniaxial compressive strength of concrete $(\mathrm{MPa})$.

For steel reinforcement, in fact, the influence of strain rate also occurs for steel bars under dynamic loading, and the longitudinal bars should have a significant impact on the bending rigidity of RC beams [23]. This eventually affects RC's dynamic response under impact loads. The DIF has also presented the effects of loading rate. In spite of the DIF definition proposed by the CEB code that may marginally reduce steel yield strength, it was proved that the CEB expressions match the experimental DIFs well for ultimate stress [24]. Thusly, the CEB terms for DIF of the strengths of the steel bars have been introduced, and the forms are as follows:

$$
\begin{aligned}
& \mathrm{YDIF}=\frac{f_{\mathrm{yd}}}{f_{\mathrm{yS}}}=1.0+\left(\frac{6.0}{f_{\mathrm{yS}}}\right) \ln \left(\frac{\dot{\varepsilon}_{s}}{\dot{\varepsilon}_{s 0}}\right), \\
& \mathrm{UDIF}=\frac{f_{\mathrm{ud}}}{f_{\mathrm{us}}}=1.0+\left(\frac{7.0}{f_{\mathrm{us}}}\right) \ln \left(\frac{\dot{\varepsilon}_{s}}{\dot{\varepsilon}_{s 0}}\right),
\end{aligned}
$$

where $f_{\mathrm{yd}}$ and $f_{\mathrm{yS}}$ are the dynamic and static yield stress and $f_{\text {ud }}$ and $f_{\text {us }}$ are the dynamic and static ultimate tensile stress, 
respectively. $\dot{\varepsilon}_{s}$ is the strain rate and $\dot{\varepsilon}_{s 0}$ the strain rate at the quasi-static state, $\dot{\varepsilon}_{s 0}=50 \times 10^{-5} \mathrm{~s}^{-1}$. It should be noted that as the character of the strain rate effect of FRP is still not evident now [25], the change of strength for FRP under high strain rate is neglected.

3.7. Contact Definition. The keyword AUTOMATIC SURFACE TO SURFACE in ABAQUS was employed to simulate the contact between the drop hammer and specimen. Defining contact between the model and itself considers a contact of pieces that crease in on the model. In any case, since contact sets take into consideration increasingly nittygritty determinations, this technique was picked. The surface to surface contact option is used to model the contact interaction. Contact sets necessitate that two surfaces be picked to contact. For the paper reported here, the whole model was allowed to contact itself by characterizing every single interior surface made by the mesh elements as one and the exterior as the second. Since contact in ABAQUS 2017 relies on the specification of primary and secondary surfaces and since analytically rigid surfaces are by default allowed to be only primary contact surfaces, here, the ripper is dependably the primary surface, and the layer including all its interior surfaces is the secondary surface. Primary surfaces force the deformation of the secondary surfaces. Nevertheless, defining contact sets, contact properties, for this situation, and the static and dynamic friction coefficients were taken as 0.3 . This type of contact is capable of considering debonding between CFRP and concrete (if it occurs) because CFRP and concrete were bonded with an epoxy adhesive in the experiment. The failure criterion of contact can be expressed as follows [26]:

$$
\left(\frac{\left|\sigma_{n}\right|}{\mathrm{NFLS}}\right)^{2}+\left(\frac{\left|\sigma_{s}\right|}{\mathrm{SFLS}}\right)^{2} \geq 1
$$

where $\sigma_{n}$ and $\sigma_{s}$ are the normal stress and shear stress of interface and NFLS and SFLS are the corresponding stress at failure, respectively. Hence, the debonding will be displayed if either of them occurs. The perfect bond was assumed between all the steel reinforcement and concrete and both components of the steel reinforcement.

3.8. Verification of the FE Models. Figure 8 shows the difference in the debonding failures of the strengthened members; as discussed above, the failure of the control specimen FH2 started with the cracking of concrete cover in the upper region of the specimen after the attainment of the peak load, followed by the failure of concrete and buckling of longitudinal steel bars in the impact hammer region and the left support (Figure 5(a)). Some cracking figure of epoxy rupture was first seen, followed by sudden failure modes of CFRP rupture. The failure modes of CFRP rupture have much appeared for members with CFRP layers. CFRP rupture occurred at the point of impact hammer and near the right support in all those members. Inspection of the members after the removal of ruptured CFRP layers and concrete cover revealed that the longitudinal steel bars had ruptured. The rupture of steel bars near a point of impact at a distance of $200 \mathrm{~mm}$ from right support was often more severe than that in the left support, as the required resistance provided by the CFRP layers is smaller at the longer sides due to the small flexural rigidity of the CFRP layers at FH2H1.

After impact, the affected elements were mainly detected at the impact and right support section. Consequently, it can be distinctly shown that the simulated configurations of crack and failure modes are inconsistent with the experimental findings.

Figure 9 presents the comparisons of time history curves of the impact force between the simulated and experimental results. It is observed that the predicted impact duration and magnitude of force compare well with the experimental results. It can thus conclude that the FE model can be capable of providing reliable results and can be further used to evaluate the performance of the RC specimen (with and without CFRP strengthening) under the impact.

3.9. Discussion on the Bending Moment. As previously mentioned, CFRP strengthening can lead the RC specimens to be governed by flexural responses under the impact. This failure mode usually is more acceptable than shear failure mode due to its greater ductility with adequate energy dissipation capacity. Thus, based on the numerical models, this section further investigates the development of bending moments of the tested specimens by using experimental results and $\mathrm{FE}$ analysis.

3.9.1. The Development of Bending Moment. Figure 10 shows the moment distribution of the strengthened and unstrengthened specimen. Especially at the initial stage $(<1 \mathrm{~ms})$ of the response, the moment curves vary with time considerably. Through the abovementioned, it can be found that the right span area of each component is a dangerous zone. The impact point section and the left and right cross section are dangerous sections. The bending moment and shear force-time history curves (Figure 10) are extracted for analysis, taking the unstrengthened and strengthened specimens impact point sections as an example. It can be observed from Figure 10(a) that the bending moments of the two members rise synchronously at the beginning of the impact force, but when it reaches about $6 \mathrm{kN} \cdot \mathrm{m}$, the unstrengthened specimen suddenly drops sharply, and the strengthened specimen can continue to bear, and it reaches a peak of $7.4 \mathrm{kN} \cdot \mathrm{m}$ at $4 \mathrm{~ms}$. After that, it remained at a high level until the steel bar broke at $11 \mathrm{~ms}$, the bending moment value began to decrease, and the bearing capacity of the member decreased rapidly. Subsequently, the bending section moment has developed along the whole length of the span, and the moment curves of both specimens gradually achieve a stable state.

Extracting the shear force of the impact point section (Figure 10(b)), it can be found that, similar to the impact time history curve, since the influence of inertial force in this area is very large, the shear peaks of unstrengthened and strengthened specimens both reach $70 \mathrm{kN}$ at the same time 


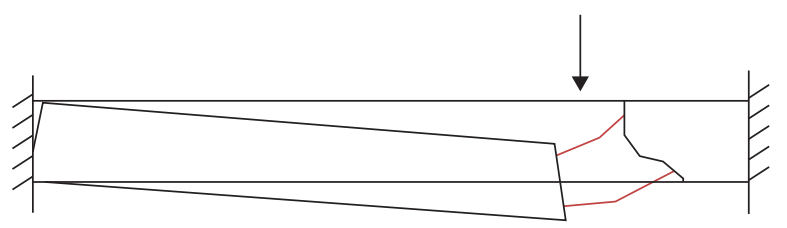

(a)

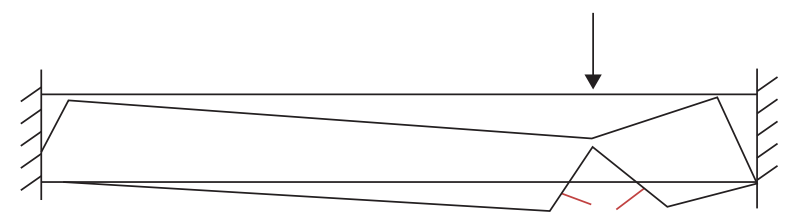

(b)

FIGURE 8: Different failure modes of specimens. (a) Unstrengthened specimen (FH2). (b) Strengthened specimen (FH2-H1).
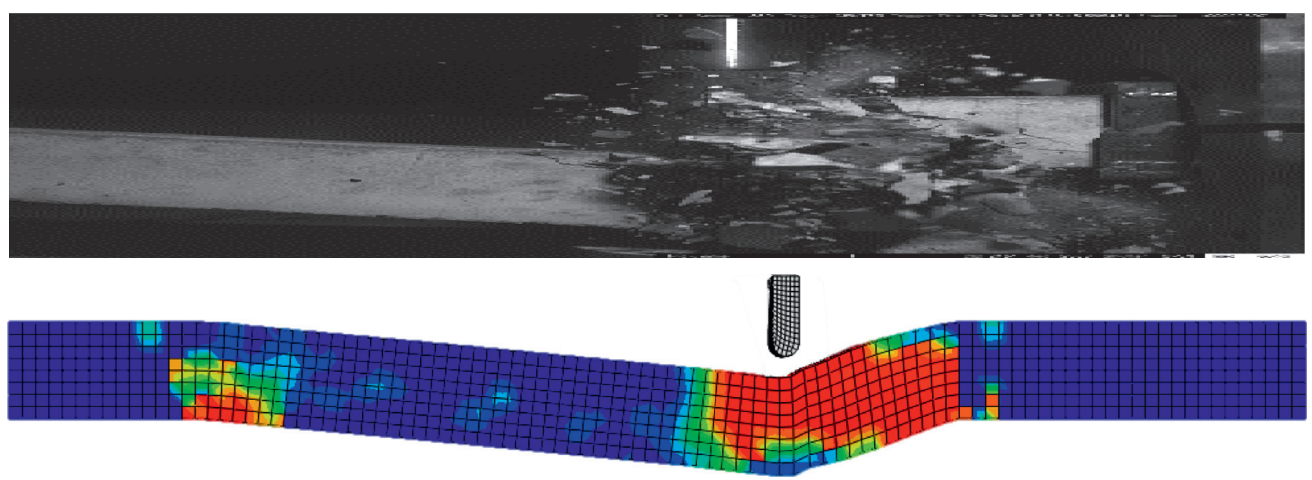

(a)
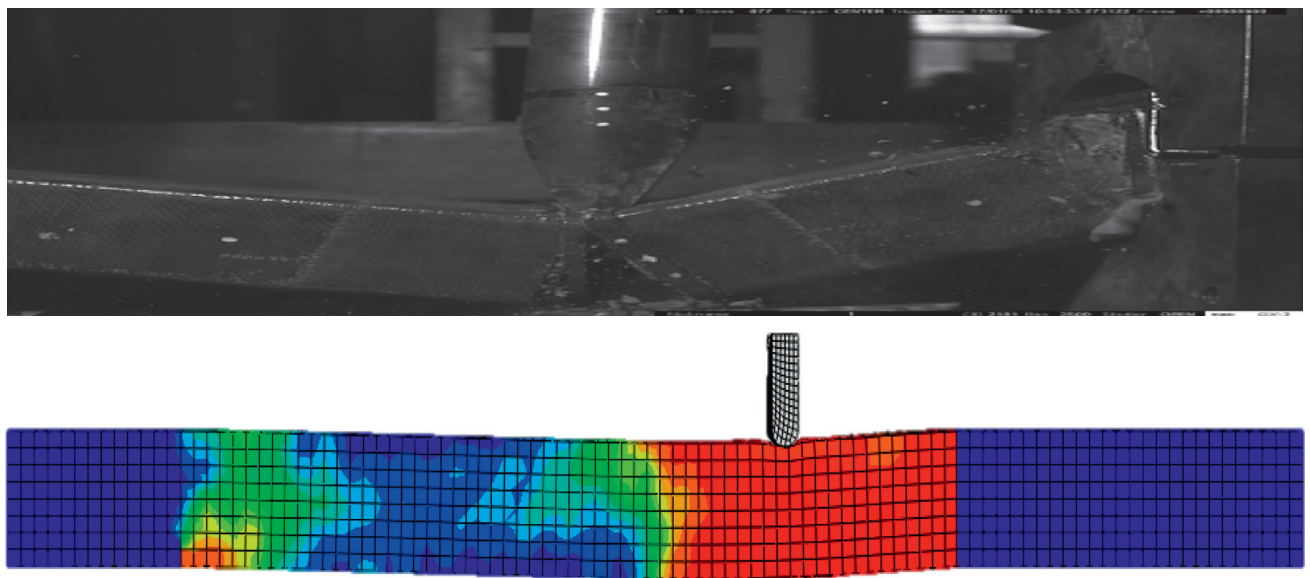

(b)

FIGURE 9: Crack patterns and failure modes from simulation. (a) Unstrengthened specimen. (b) Strengthen specimen.

under acceleration and then immediately drop. After falling below $20 \mathrm{kN}$, the components are gradually weakened by the degradation of inertial force, and the bearings at both ends gradually begin to bear. At this time, the shear force of the strengthened specimen rises back to $60 \mathrm{kN}$ or more. Finally, it started to fall around $10 \mathrm{~ms}$, which is consistent with the time when the strengthened specimen steel bar broke. The difference is that the shear force of the unstrengthened specimen rises to about $35 \mathrm{kN}$ around $18 \mathrm{~ms}$, and it cannot continue to bear. It starts to fluctuate between $20 \mathrm{kN}$ and $40 \mathrm{kN}$. This is because the concrete is greatly affected by shear crack after $8 \mathrm{~ms}$ (Figure 5(a)), unable to withstand higher vertical loads. However, it should be noted that compared with the unstrengthened specimen, the envelope of bending moment for the strengthened specimen is significantly bigger, indicating the possibility of forming a plastic hinge at or near these critical sections.

These phenomena show clearly that the brittle shear failure can make the unstrengthened specimen unable to exhibit its flexural capacity fully; on the other hand, a typical flexural deformation mechanism can occur on the RC specimen after strengthening with shear-CFRP under the impact load.

3.10. Dynamic Amplification Factor (DAF) for Bending Moment. The dynamic amplification factor (DAF) [27] for the plastic moment is employed here to quantify the flexural performance of the specimen under the impact load. The larger the DAF is, the closer the specimen is to the pure 


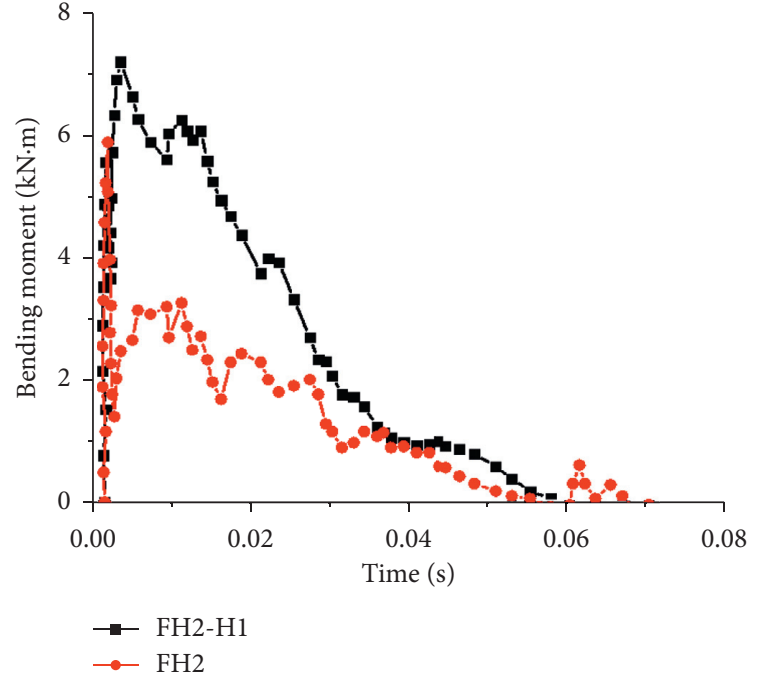

(a)

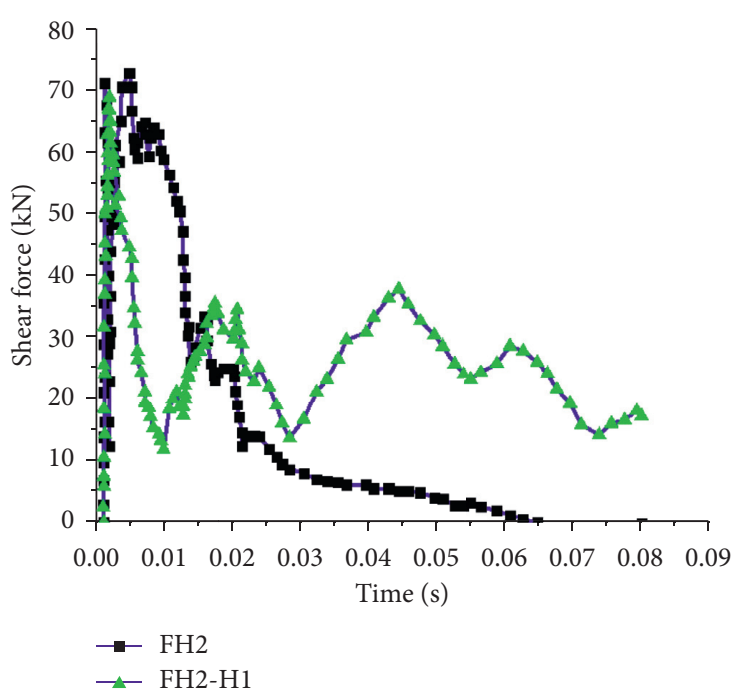

(b)

Figure 10: Time-history curve of the bending moment for the impact point section. (a) Bending moment time history curve. (b) Shear time history curve.

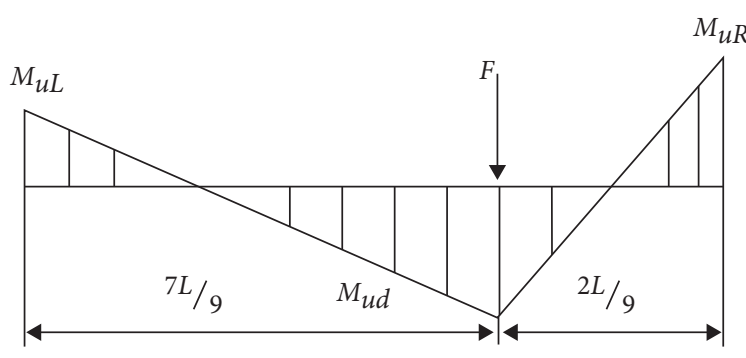

(a)

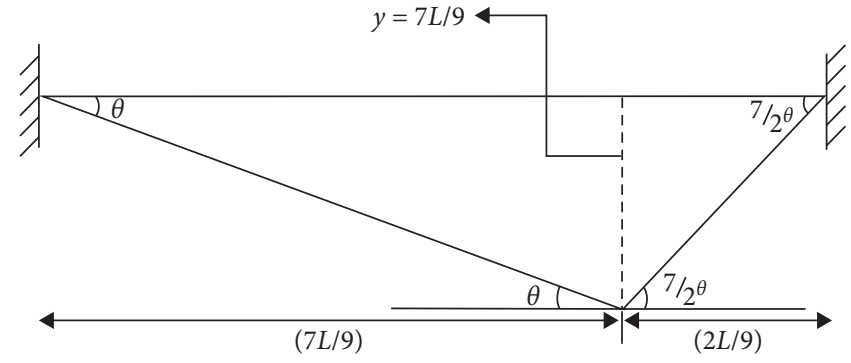

(b)

Figure 11: The specimen subjected to (a) a concentrated load at the (2/9) $L$ of span and (b) plastic hinge.

bending deformation state. The DAF can be expressed as follows:

$$
\mathrm{DAF}=\frac{M_{\mathrm{ud}}}{M_{\mathrm{us}}},
$$

where $M_{\mathrm{ud}}$ is the dynamic plastic moment; it can be taken as the average steady moment as described in the section of the development of bending moment above; $M_{\mathrm{us}}$ is the plastic moment under static load. It is noted that $M_{\text {us }}$ here was taken as $4.9 \mathrm{kN} \cdot \mathrm{m}$, which was calculated by the nonlinear section analysis program Response-2000. This program code is based on the modified pressure field theory (MPFT), which is capable of evaluating the stress state of the RC beam or column under bending-shear coupling effects. On the other hand, $M_{\mathrm{ud}}$ can be calculated in two ways: (1) based on recorded impact forces and (2) derived directly from the numerical model.

\subsubsection{Based on Recorded Impact Forces (Kinematic Method).} The tested specimen with an effective span $L$ subjected to a concentrate load $F$ at the $2 L / 9$ of the span is shown in Figure 11. As $F$ increases, a plastic hinge develops at both the supports and the impact section. Therefore, according to the virtual work [28], the plastic moment can be obtained as follows:

$$
\begin{aligned}
& \text { work external }=\text { work internal, } \\
& \qquad \begin{aligned}
f \times \frac{7 l}{9}=M_{\mathrm{ud}}+M_{\mathrm{ud}} \times\left(\frac{4}{2}\right)+M_{\mathrm{ud}} \times\left(\frac{7}{2}\right) . \\
M_{\mathrm{ud}}=\frac{7 F L}{81} .
\end{aligned}
\end{aligned}
$$

It is noted that $F$ here can be considered equal to $F_{\text {plateau }}$ obtained in the test, as summarized in Table 2. Moreover, the dynamic plastic moment and the dynamic amplification factor based on test results ( $M_{\mathrm{ud} 1}$ and $\mathrm{DAF}_{1}$, respectively) can thus be calculated according to (6) and (8), as summarized in Table 2.

3.10.2. Derived from the Numerical Models. The moment versus the impact point deflection curves derived from the numerical simulation is shown in Figure 10(a). It should be 
TABle 2: Comparison of the tested specimens.

\begin{tabular}{|c|c|c|c|c|c|c|c|c|c|}
\hline Specimen & $\begin{array}{l}\text { Size } \\
\left(\mathrm{mm}^{2}\right)\end{array}$ & $\begin{array}{l}\text { Drop height } \\
(\mathrm{mm})\end{array}$ & $\begin{array}{l}\text { Wrapping scheme of } \\
\text { CFRP }\end{array}$ & $\begin{array}{c}F_{\text {plateau }} \\
(\mathrm{kN})\end{array}$ & $\begin{array}{c}M_{\mathrm{us}} \\
(\mathrm{kNm})\end{array}$ & $\begin{array}{c}M_{\mathrm{ud} 1} \\
(\mathrm{kNm})\end{array}$ & $\begin{array}{c}M_{\mathrm{ud} 2} \\
(\mathrm{kNm})\end{array}$ & $\mathrm{DAF}_{1}$ & $\mathrm{DAF}_{2}$ \\
\hline $\begin{array}{l}\text { Unstrengthened } \\
\text { specimen }\end{array}$ & \multirow[b]{2}{*}{120} & \multirow[b]{2}{*}{5} & No CFRP & 38 & \multirow[b]{2}{*}{4.9} & 1.62 & 2.8 & 0.33 & 0.57 \\
\hline $\begin{array}{l}\text { specimen } \\
\text { Strengthened } \\
\text { specimen }\end{array}$ & & & Continuous wrapping & 64 & & 5.56 & 4.6 & 1.13 & 0.94 \\
\hline
\end{tabular}

noted that the relatively steady moment described in Section 3.10.1 could be defined as the dynamic plastic moment. As the curves are dynamic, the average value for a dynamic plastic moment was employed to calculate the dynamic plastic moment and the dynamic amplification factor from the numerical simulation $\left(M_{\mathrm{ud} 2}\right.$ and $\mathrm{DAF}_{2}$, respectively). The final values are listed in Table 2 . As shown in Table 2, the difference between the $\mathrm{DAF}_{1}$ and $\mathrm{DAF}_{2}$ is small; this again demonstrates the reliability of the FE model established in the present study. It is found that the DAF for strengthened RC specimen is close to 1.2, while the value for the unstrengthened RC specimen is about 0.5, meaning the plastic moment of the unstrengthened specimen under the impact is almost unchanged compared to that under the static load. Additionally, it is noted that Lee et al. [29, 30] have conducted a numerical investigation on the DAF of RC beams under impact load. The beams were found exhibiting the combined mode of shear and flexural damage after impact. The authors finally obtained an average DAF of 0.45 for the tested beams; this value is still smaller than the value of the CFRP-shear-strengthened specimen obtained in the present study. These phenomena indicate that the shear damage could affect the flexural performance considerably, while the RC specimen strengthened with CFRP in shear tend to be closer to the pure bending deformation under the impact load, and the flexural capacity in critical sections of the specimen can thus be fully achieved.

3.11. Parametric Study on Flexural Performance. The parametric study conducted in this section aims to provide an extensive understanding of how to achieve a better strengthening effect, that is, making the RC specimen exhibit better flexural performance, with the various kinds of CFRPrelated parameters. The main parameters include impact velocity, reinforcement ratio, and concrete strength grade and CFRP layers. All specimens in this section are continuously wrapped along the span. The impact speed is set to $3 \mathrm{~m} / \mathrm{s}$, and the mass of the drop hammer is $270 \mathrm{~kg}$.

3.12. Impact Velocity Effects. The maximum deflection at different impact velocities from the CFRPRC components (Figure 12) can be observed. The deflection of the FH2 component is significantly more than that of the $\mathrm{FH} 2-\mathrm{H} 1$ component at the same speed. However, the deflection of the $\mathrm{FH} 2-\mathrm{H} 1$ component is irregular, and the deflection is significantly increased after $4.0 \mathrm{~m} / \mathrm{s}$. So, the maximum midspan deflection increases linearly with increasing impact speed. This observation is in good agreement with the experimental observations in $[31,32]$, and as Jin et al. said in his study, the

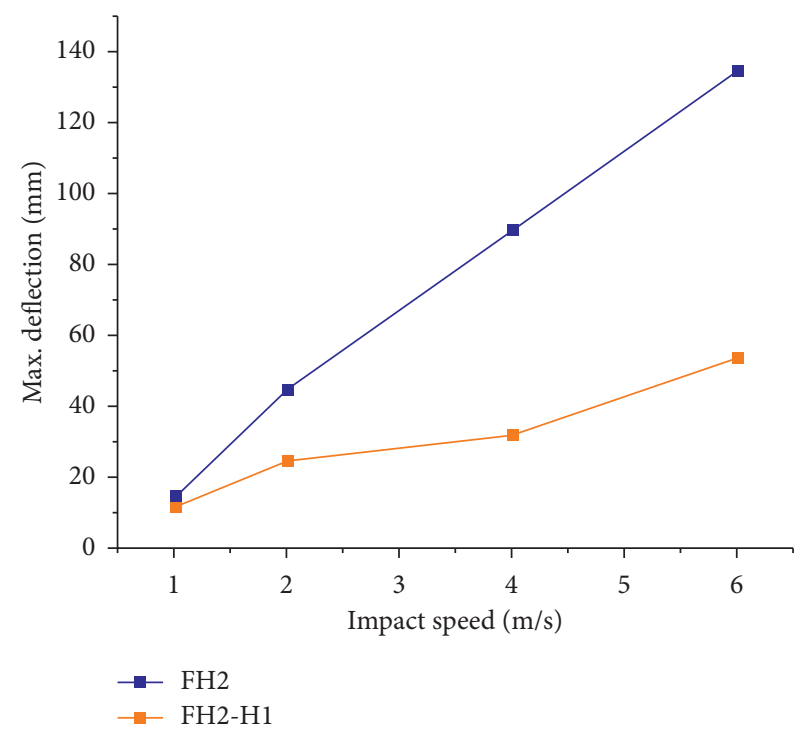

FIGURE 12: Speed-maximum deflection relationship.

maximum midspan deflection increases linearly with an increasing hammer height (which exhibit different impact velocities), and that is the same as in this paper for impact speed [33].

The steel bars of the CFRPRC members will be a success to the resistance of deflection only in $\mathrm{FH} 2-\mathrm{H} 1$, which has a significant influence on the deformation resistance of the members. Figures 13-15 show the impact force and duration of all components at each stage under different impact speeds. It can be seen that as the impact velocity increases, the peak value of the component impact force will increase accordingly. In the comparison of the impact plateau force (Figure 14), it can be observed that the plateau force of the $\mathrm{FH} 2-\mathrm{H} 1$ component is greater than that of the $\mathrm{FH} 2$ component at the same speed when the impact velocity is increased from $1 \mathrm{~m} / \mathrm{s}$ to $2 \mathrm{~m} / \mathrm{s}$ and from $2 \mathrm{~m} / \mathrm{s}$ to $4 \mathrm{~m} / \mathrm{s}$. The impact force has significantly increased values for all components. Still, the difference is that when the impact velocity increases from $4.0 \mathrm{~m} / \mathrm{s}$ to $6.0 \mathrm{~m} / \mathrm{s}$, the peak force of each component hardly changes. This shows that the FH2 component and the $\mathrm{FH} 2-\mathrm{H} 1$ component have reached the maximum load state at an impact velocity of $4.0 \mathrm{~m} / \mathrm{s}$ and thereafter continue to increase the impact velocity, and each component can only rely on the increase of deformation to continue consuming the impact energy. For FH2-H1 bending deformation member, when the deformation is too large, the longitudinal reinforcement reaches the ultimate strain fracture, which will lead to a decrease in the stiffness and the deformation of the component. Because of the 


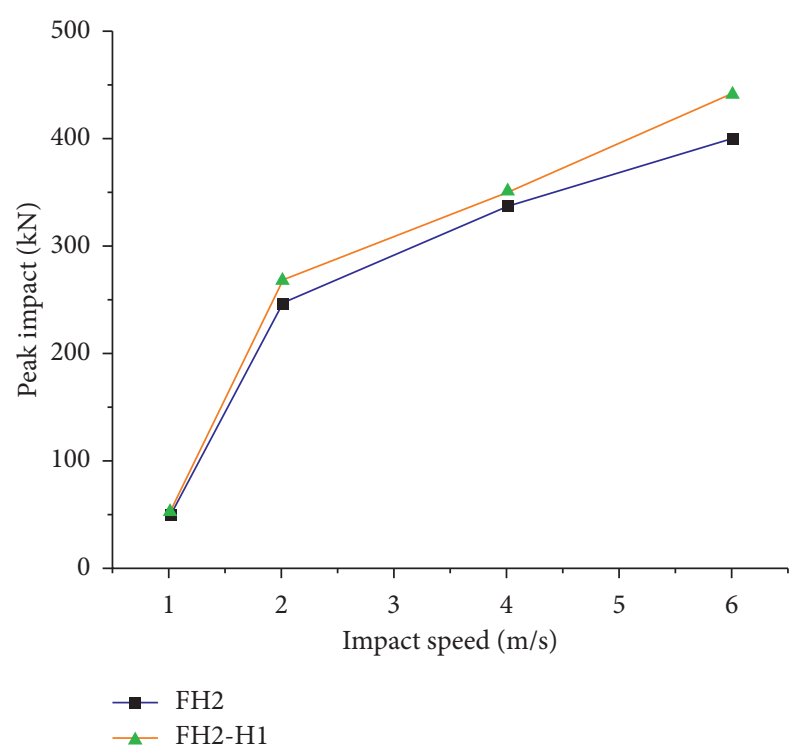

FIGURE 13: Speed-impact peak relationship.

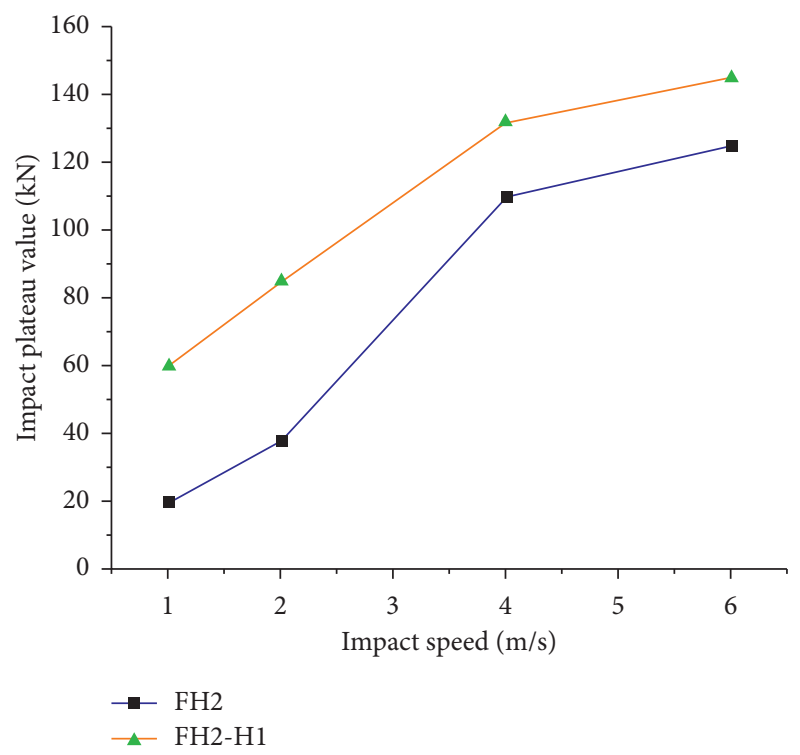

FIGURE 14: Speed-impact plateau value relationship.

fracture of the steel, the deflection of the $\mathrm{FH} 2-\mathrm{H} 1$ member is stronger at $4.0-6.0 \mathrm{~m} / \mathrm{s}$. The component rises linearly with increasing speed (Figure 12). Similarly, at the speed of $4.0-6.0 \mathrm{~m} / \mathrm{s}$, the duration of the $\mathrm{FH} 2-\mathrm{H} 1$ component platform is significantly increased (Figure 15). From the above analysis, it can be stated that the $\mathrm{FH} 2-\mathrm{H} 1$ component has better resistance to deformation and bearing capacity than the $\mathrm{FH} 2$ component of the same condition on the premise that the longitudinal reinforcement does not occur. In contrast, $\mathrm{FH} 2-\mathrm{H} 1$ has better resistance to deformation and bearing capacity than the $\mathrm{FH} 2$ component.

3.13. Effect of Reinforcement Ratio. Due to the rupturing of the longitudinal reinforcement caused by the CFRP-

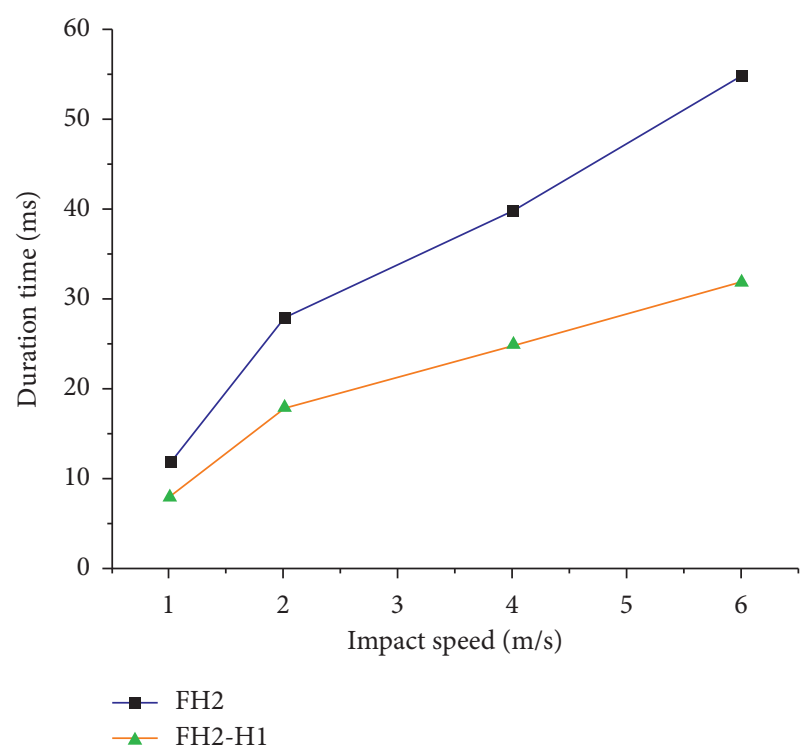

FIgURE 15: Speed-impact duration time relationship.

reinforced RC members in the part of (experimental Program), the impact resistance of the members is affected. In this section, the reinforcement ratio is changed by increasing the diameter of the longitudinal reinforcement, and the influence of different reinforcement ratios on the reinforcement effect of CFRP is discussed. In addition to the longitudinal steel bars with a reinforcement ratio of $2 \%$ in the test, the reinforcement ratios $0.78 \%$ and $4.5 \%$ were also considered for the CFRPRC members. It can be found that the deformation and failure mode of the most CFRP-RC members after changing the diameter of the longitudinal reinforcement with a low ratio has not changed significantly, compared to $\mathrm{FH} 2-\mathrm{H} 1$. That indicates that the specimen CFRP-CR strongly resists the shear stresses. When the reinforcement ratio is $2 \%$, the cracks' width is significantly smaller than the scenario with a low reinforcement ratio because of increased reinforcement diameter. When the reinforcement ratios are $4.5 \%$, so there are no cracks with the longitudinal reinforcement. Figures 16(a)-16(d) show the peak, impact force, duration, and maximum deflection of each component at each stage. It can be seen that the reinforcement ratio has little effect on the peak impact of each component. As the reinforcement ratio increases, there is a slight increase in peaks; this may be because the increase in the amount of reinforcing steel increases the mass of the entire component, thereby amplifying the inertial force effect of the component at the peak stage.

From the other indicators, it can be found that the shear failure of the FH2 component is less affected by the reinforcement ratio. There is almost no change in the impact of platform value and duration. However, for the rest of CFRPRC members with bending deformation, the impact force is very sensitive to the reinforcement ratio. Similar to the rest of the indicators, the deflection of the FH2 component did not change significantly. However, the deflection of the CFRP-RC components is significantly reduced as the reinforcement ratio increases. CFRP-RC members with a 


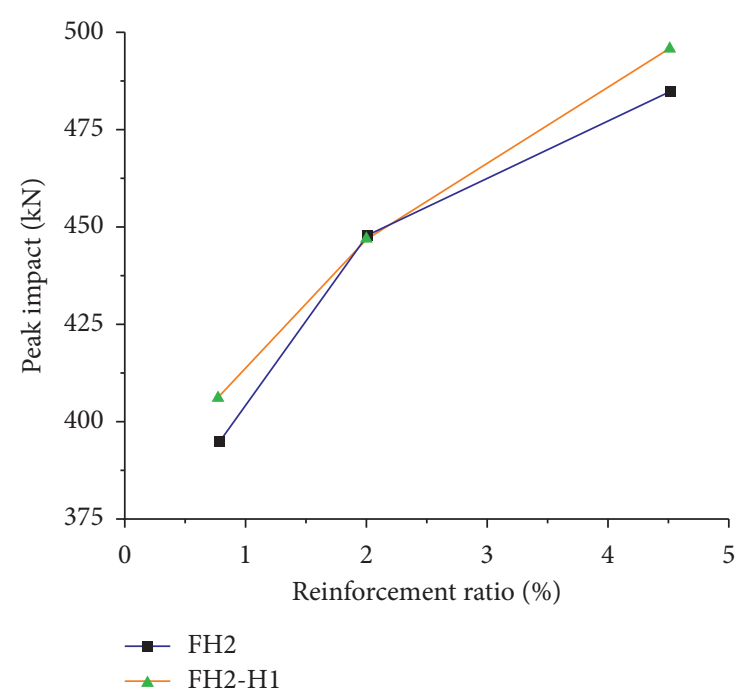

(a)

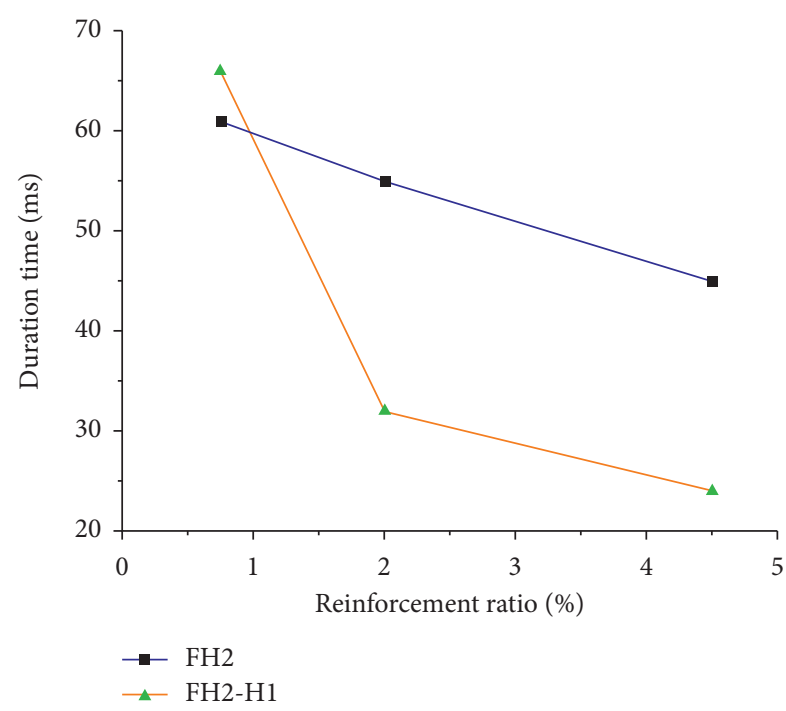

(c)

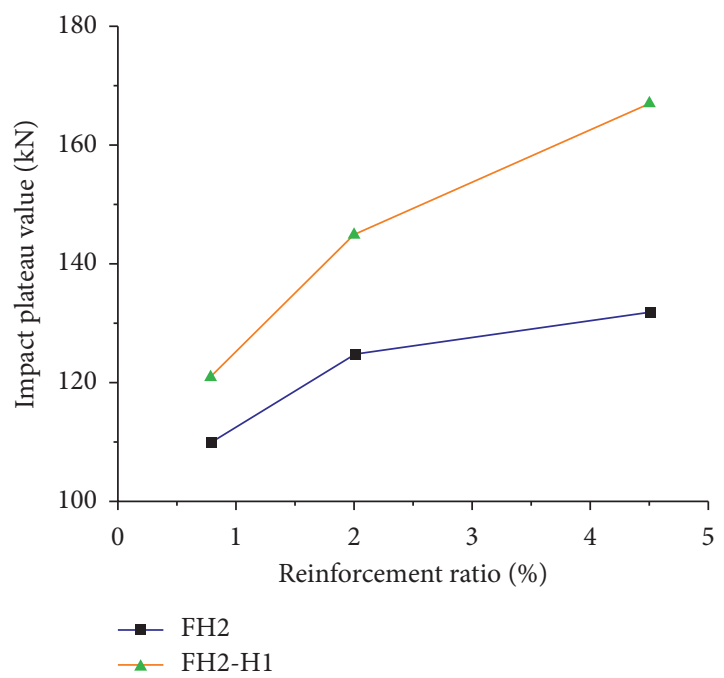

(b)

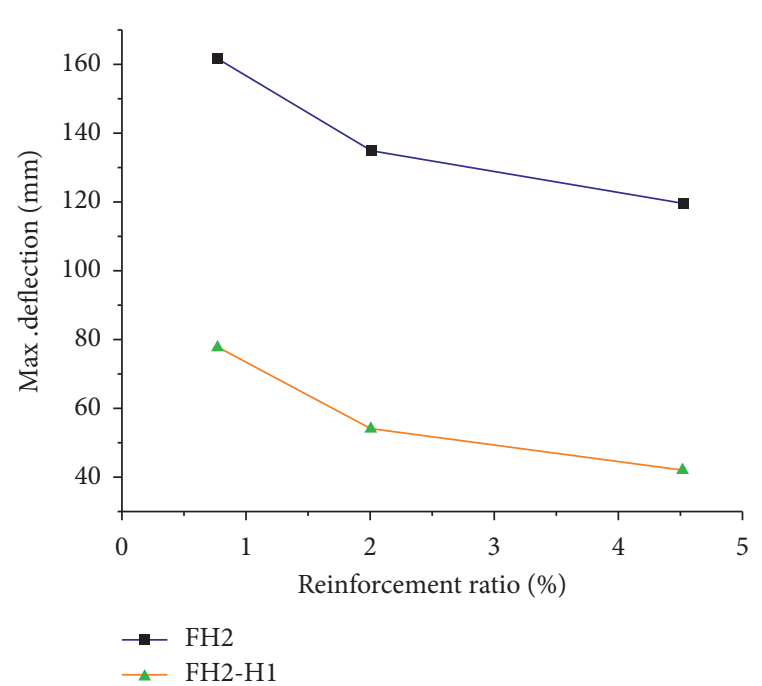

(d)

FIGURE 16: The effect of reinforcement ratio on the forces. (a) Reinforcement ratio-impact peak relationship. (b) Reinforcement ratio-impact force platform value relationship. (c) Reinforcement ratio-impact time duration relationship. (d) Reinforcement ratio-maximum deflection relationship.

reinforcement ratio of $4.6 \%$ have a maximum deflection of only $22 \mathrm{~mm}$. It is much smaller than $123 \mathrm{~mm}$ of the $\mathrm{FH} 2$ member under the same conditions.

3.14. Effects of Concrete Strength. It can be seen that the peak impact force increases with the increase of concrete strength, but it still grows minimal $(<5 \%)$; the impact force platform value also increases slightly, which also makes the corresponding decrease. However, it is worth noting that when the concrete strength is $90 \mathrm{MPa}$, the impact force platform value of the CFRP-RC members is more stable, and there is no large fluctuation, which may be due to the reduction of the failure mode of the working condition (Figure 17). The right span concrete did not wholly lose its bearing capacity during the impact process so that the connection between the longitudinal ribs and the stirrups was not destroyed. For this reason, it can be seen from Figure 18 that when the concrete strength is increased by $90 \mathrm{MPa}$ from $43.5 \mathrm{MPa}$, the deflection of the CFRP-RC members is the smallest in all working conditions, indicating that the deformation of the CFRP-RC members is greatly affected by the concrete strength. The deflection time history (Figure 18) of the other working conditions will decrease with the increase of concrete strength, which is due to the ductility of the components [34], but the amplitude is not large (less than $10 \%)$. The ultimate compressive strength of concrete in the test is $43.5 \mathrm{MPa}$. In this section, the strength of concrete is 


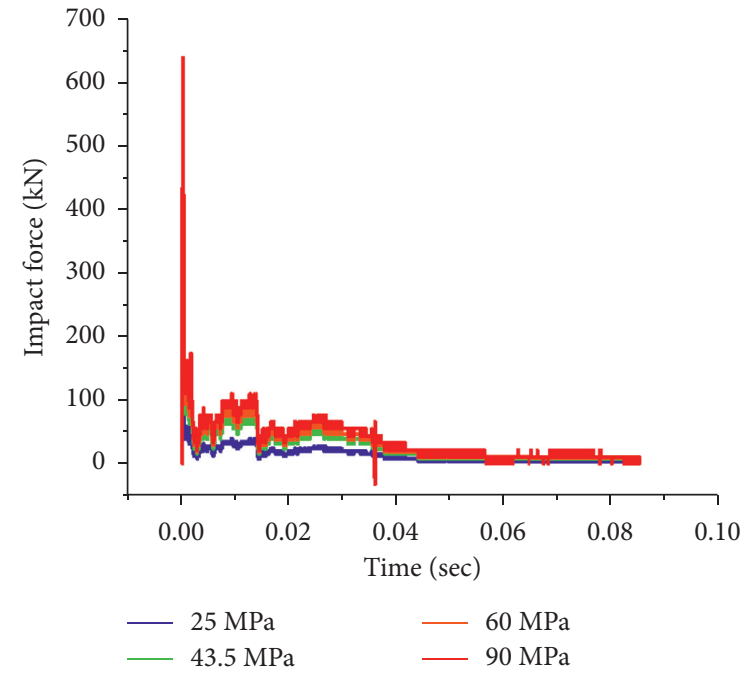

(a)

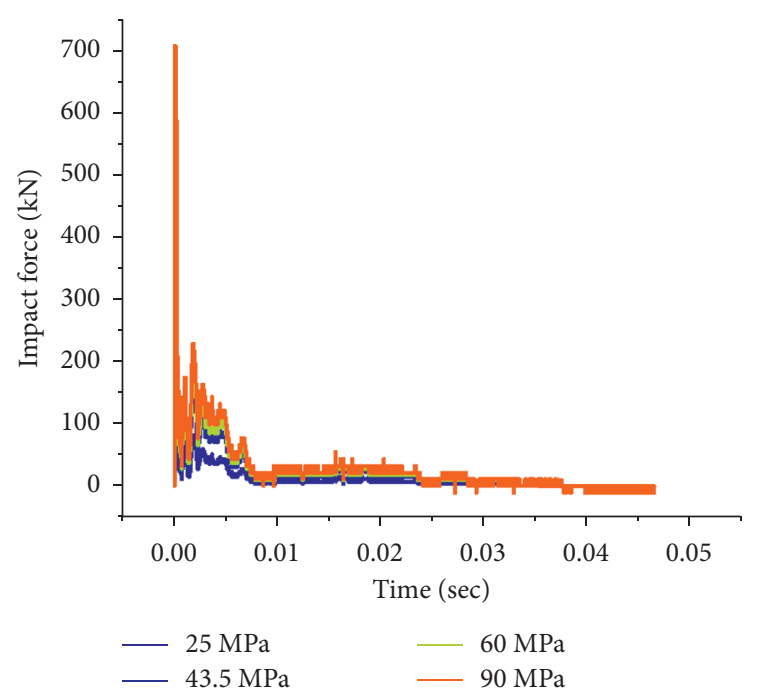

(b)

FIGURE 17: Effect of concrete strength on the impact time history curve of (a) FH2 specimen and (b) FH2-H1 specimen.

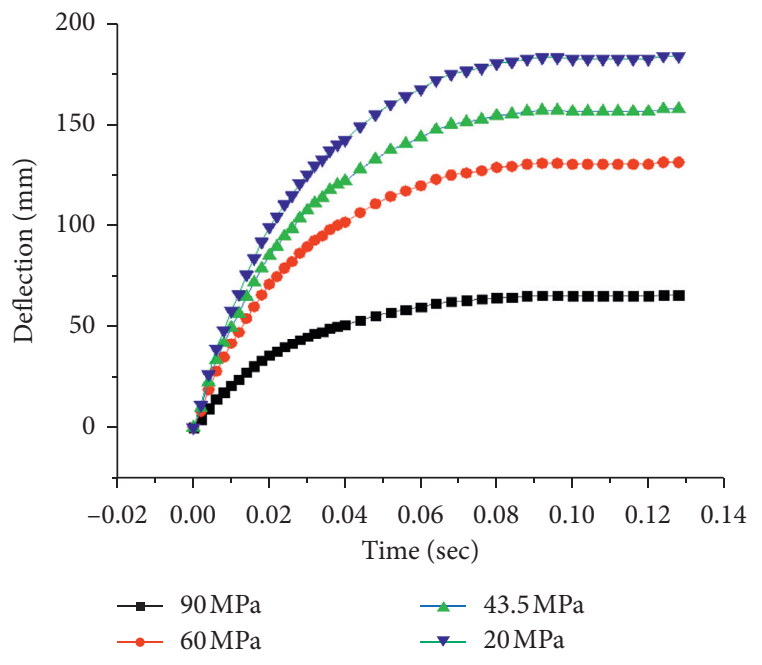

(a)

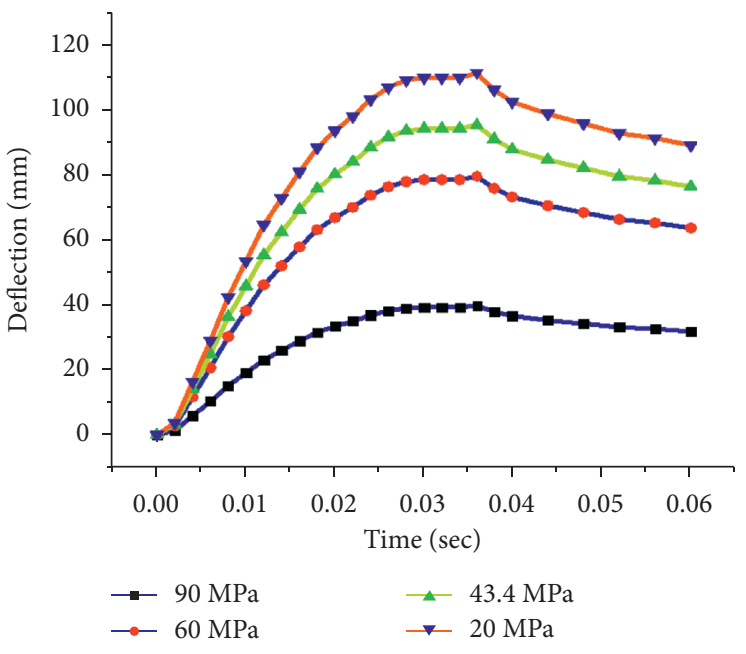

(b)

FIGURE 18: Effect of concrete strength on the deflection time history curve of CFRPRC members. (a) FH2. (b) FH2-H1.

improved by three levels, namely, $25 \mathrm{MPa}, 60 \mathrm{MPa}$, and $90 \mathrm{MPa}$, by finite element simulation. The influence of concrete strength on CFRPRC-reinforced members is discussed. Figure 18 shows the failure modes of the members at maximum deflection at different compressive strengths. It can be found that the concrete has a great influence on the failure modes of all members. As the strength of the concrete increases, the failure area of the member decreases.

3.15. Effects of Number of CFRP Layers. Figures 19(a) and 19(b) compare the impact force and maximum deflection of reinforced components with 1-4-6 layers of CFRP components. It can be found that when the number of layers changes from 0 to 1 , the peak impact values and displacement of the members are all very obvious. This is because the reinforcement of the one layer CFRP not only provides the shear resistance of the original RC components but also directly changes its deformation mode, which improves the overall deformation ability of the component, resulting in a significant increase in impact resistance. However, when the number of layers changes from 1 to 4 layers, there is no significant change in the indicators of the components, which may be due to the impact energy and component performance of these components. In contrast, when the number of layers changes from 4 to 6 layers, there is a significant change in the indicators of the components, resulting in a significant increase in impact resistance and maximum deformation. The one-layer CFRP has been able to provide sufficient lateral bearing capacity for the 


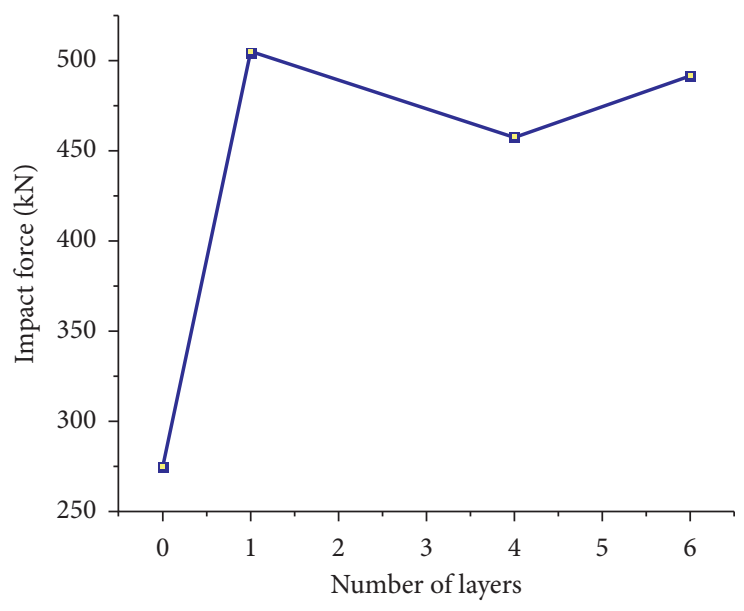

(a)

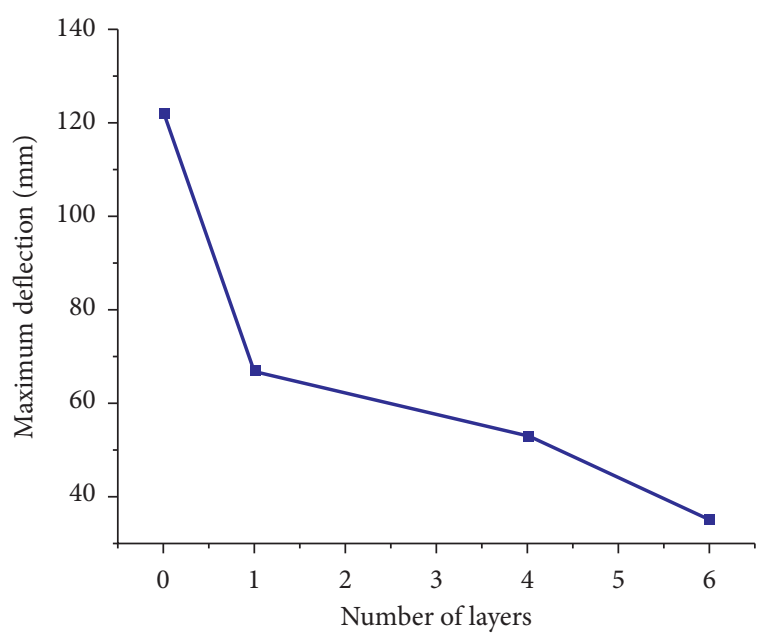

(b)

FIGURE 19: (a) Effect of CFRP layers on a maximum deflection of components. (b) Effect of CFRP layers on impact force of components.

component to maintain the component in an overall flexed state [35]. At this time, the resistance of the member is controlled by its bending strength, and the excessive number of layers does not provide greater rigidity for impact force to the member but provides the greatest stiffness for deflection to the member, and that is in agreement with Lat. Am et al. study [36].

\section{Conclusions}

Based on the impact test on RC specimen with and without CFRP strengthening in shear and the numerical simulation presented in this paper, the following conclusions can be drawn:

(i) Experimental results showed that using CFRP to strengthen RC specimen in shear can effectively avoid shear failure and lead the RC specimen to be governed by flexural responses under the impact load but may also cause the longitudinal reinforcement bars to be fractured. This case needs additional consideration.

(ii) FE model proposed in this paper agreed reasonably with the experimental results in terms of time history curves of impact force, lateral deflection, and failure modes.

(iii) RC specimen externally strengthened with CFRP in shear is prone to develop pure bending deformation under the trans-lateral impact load; thus, the specimen can reach full flexural capacity.

(iv) While the FH2-H1 component loses part of the bending stiffness and the vertical bearing capacity due to the occurrence of the steel bar fracture, the bending moment tends to decrease step by step, but the bending bearing capacity can be continuously provided throughout the impact process and relatively large shear.

(v) In contrast, with FH2-H1 component high strength resistance for bending and vertical bearing capacity due to the stiffness of concrete, steel bar, and layers of CFRP, so CFRP reinforced $\mathrm{RC}$ members can improve the shear resistance and overall bending deformation of the members.

(vi) In this paper, the dynamic amplification factor (DAF) for the plastic moment did employ to measure the flexural performance of specimen under impact load. It was indicated that, the larger the DAF is, the nearer the specimen is to the condition of pure bending deformation.

(vii) The longitudinal reinforcement ratio has a relatively small influence on the $\mathrm{FH} 2$ specimen but has a great influence on the $\mathrm{FH} 2-\mathrm{H} 1$ specimen. The increase of the reinforcement ratio increases the energy consumption of the specimen and effectively prevents the fracture of the steel bar of the $\mathrm{FH} 2-\mathrm{H} 1$ specimen. It is indicated that the use of CFRP to strengthen RC specimens with a high longitudinal reinforcement ratio can achieve better reinforcement.

(viii) Concrete strength has a limited impact on the impact of CFRPRC specimens, but the higher the strength of the concrete will help to reduce the damage to the damaged area of each component. Especially for the FH2 specimen, when the concrete strength is $90 \mathrm{MPa}$, the damage degree of the specimen is the slightest, so the deflection of the specimen is also reduced to some extent.

(ix) One-layer CFRP can already lead the RC specimen to be flexural-dominated. The change is minimal when wrapped with extra layers of CFRP.

\section{Data Availability}

All data included in this study are available upon request to the corresponding author. 


\section{Conflicts of Interest}

The authors declare that they have no conflicts of interest.

\section{Acknowledgments}

This research was funded by the National Natural Science Foundation of China (Grant no. 51378427) and the National Key Research and Development Program of China (Grant no. 2016YFC0802205-9).

\section{References}

[1] G. Kashwani, A. Al-Tamimi, R. A. Hawileh, and J. A. Abdalla, "Behaviour of RC beams strengthened with CFRP laminates under quasi-static cyclic loading," in Proceedings of the 2nd International Conference on Future Concrete, Dubai, UAE, 2011.

[2] H. Niu and Z. Wu, "Effects of FRP-concrete interface bond properties on the performance of RC beams strengthened in flexure with externally bonded FRP sheets," Journal of Materials in Civil Engineering, vol. 18, no. 5, pp. 723-731, 2006.

[3] H. Varum, F. Teixeira-Dias, P. Marques, A. V. Pinto, and A. Q. Bhatti, "Performance evaluation of retrofitting strategies for non-seismically designed RC buildings using steel braces," Bulletin of Earthquake Engineering, vol. 11, no. 4, pp. 11291156, 2013.

[4] H. Zhang, D. Kong, H. Wu, X. Ding, and Q. Kou, "Flexural behavior of concrete beams strengthened with near-surface mounted GFRP bars," Industrial Construction, vol. 2, pp. 1379-1384, 2010.

[5] Y. Z. Zheng, X. G. Wang, and H. Q. Chen, "Behavior of support zone of cantilever beam embeded with FRP tendons," Engineering Mechanics, vol. 29, pp. 75-78, 2012.

[6] S. M. Soleimani and N. Banthia, "A novel drop weight impact setup for testing reinforced concrete beams," Experimental Techniques, vol. 38, no. 3, pp. 72-79, 2014.

[7] E. Shafei and M. Z. Kabir, "Effects of CFRP retrofit on impact response of shear-deficient scaled reinforced concrete beams," Latin American Journal of Solids and Structures, vol. 12, no. 1, pp. 60-76, 2015.

[8] T. M. Pham and H. Hao, "Prediction of the impact force on reinforced concrete beams from a drop weight," Advances in Structural Engineering, vol. 19, no. 11, pp. 1710-1722, 2016.

[9] T. Liu and Y. Xiao, "Impact behavior of CFRP-strip-wrapped RC beams without stirrups," Journal of Composites for Construction, vol. 21, no. 5, 2017.

[10] “Torayca ${ }^{\circledR}$ cloth," 1999, https://pdfslide.tips/documents/toraycacloth-of-const-ruct-ion-dated-dec-ember-1999-1-2.html.

[11] HUNTSMAN, Construction Adhesives the Classics Stick to the Future.

[12] D 3039/D3039M ASTM, Standard Test Method for Tensile Properties of Polymer Matrix Composite Materials, ASTM Internaional, West Conshohocken, PA, USA, 2000.

[13] K. Fujikake, B. Li, and S. Soeun, "Impact response of reinforced concrete beam and its analytical evaluation," Journal of Structural Engineering, vol. 135, no. 8, pp. 938-950, 2009.

[14] S. Adhikary, B. Li, and K. Fujikake, "Low velocity impact response of reinforced concrete beams: experimental and numerical investigation," International Journal of Protective Structures, vol. 6, no. 1, 2015.

[15] ABAQUS, “Dassault systèmes ${ }^{\circledR}, ” 2020$, https://www.3ds.com/ products-services/simulia/products/abaqus/latest-release/.
[16] D. Hibbitt, B. Karlsson, and P. Sorensen, ABAQUS 6.10 Analysis User's Manual, Dassault Simulia, Pawtucket, RI, USA, 2010.

[17] Ö. Anil, R. Tuğrul Erdem, and M. N. Tokgöz, "Investigation of lateral impact behavior of RC columns," Computers and Concrete, vol. 22, no. 1, pp. 123-132, 2018.

[18] D. Levi-Hevroni, E. Kochavi, B. Kofman, S. Gruntman, and O. Sadot, "Experimental and numerical investigation on the dynamic increase factor of tensile strength in concrete," International Journal of Impact Engineering, vol. 114, pp. 93104, 2018.

[19] X. Yan and S. Yali, "Impact behaviors of CFT and CFRP confined CFT stub columns," Journal of Composites for Construction, vol. 16, no. 6, pp. 662-670, 2012.

[20] Ceb-Fip and CMC90, Design of Concrete Structures. CEB-FIP Model Code 1990, Thomas Telford, London, UK, 1993.

[21] X. Q. Zhou and H. Hao, "Modelling of compressive behaviour of concrete-like materials at high strain rate," International Journal of Solids and Structures, vol. 45, no. 17, pp. 4648-4661, 2008.

[22] L. J. Malvar and C. A. Ross, "Review of strain rate effects for concrete in tension," ACI Materials Journal, vol. 95, no. 6, pp. 735-739, 1998.

[23] S. C. K. Yuen and G. N. Nurick, "Experimental and numerical studies on the response of quadrangular stiffened plates. Part I: subjected to uniform blast load," International Journal of Impact Engineering, vol. 31, no. 1, pp. 55-83, 2005.

[24] CEB-FIP, Model Code 1990, Com, Euro-International Du Beton, Paris, France, 1991.

[25] Y. Cao, M. Liu, Y. Zhang, J. Hu, and S. Yang, "Effect of strain rates on the stress-strain behavior of FRP-confined predamaged concrete," Materials (Basel), vol. 13, no. 5, 2020.

[26] C. A. Coronado and M. M. Lopez, "Sensitivity analysis of reinforced concrete beams strengthened with FRP laminates," Cement and Concrete Composites, vol. 28, no. 1, pp. 102-114, 2006.

[27] M.-H. Tsai and B.-H. Lin, "Dynamic amplification factor for progressive collapse resistance analysis of an RC building," The Structural Design of Tall and Special Buildings, vol. 18, no. 5, pp. 539-557, 2009.

[28] S. S. J. Moy, Plastic Methods for Steel and Concrete Structures, Macmillan International Higher Education, Montgomery, AL, USA, 1981.

[29] J. Lee and G. L. Fenves, "Plastic-damage model for cyclic loading of concrete structures," Journal of Engineering Mechanics, vol. 124, no. 8, 2002.

[30] T. M. Pham and H. Hao, "Effect of the plastic hinge and boundary conditions on the impact behavior of reinforced concrete beams," International Journal of Impact Engineering, vol. 102, pp. 74-85, 2017.

[31] S. Tachibana, H. Masuya, and S. Nakamura, "Performance based design of reinforced concrete beams under impact," Natural Hazards and Earth System Sciences, vol. 10, no. 6, pp. 1069-1078, 2010.

[32] B. Xu and X. Zeng, "Experimental study on the behaviors of reinforced concrete beams under impact loadings," Journal of Civil Engineering, vol. 41, no. 2, pp. 51-61, 2014.

[33] L. Jin, J. Xu, R. Zhang, and X. Du, "Numerical study on the impact performances of reinforced concrete beams: a mesoscopic simulation method," Engineering Failure Analysis, vol. 80, pp. 141-163, 2017.

[34] A. K. H. Kwan, J. C. M. Ho, and H. J. Pam, "Flexural strength and ductility of reinforced concrete beams," Proceedings of the 
Institution of Civil Engineers-Structures and Buildings, vol. 152, no. 4, pp. 361-369, 2002.

[35] M. Kim, A. Pokhrel, D. Jung, S. Kim, and C. Park, "The strengthening effect of CFRP for reinforced concrete beam," Procedia Engineering, vol. 210, pp. 11-12, 2017.

[36] M. A. Mashrei, J. S. Makki, and A. A. Sultan, "Flexural strengthening of reinforced concrete beams using carbon fiber reinforced polymer (CFRP) sheets with grooves," Latin American Journal of Solids and Structures, vol. 16, no. 4, 2019. 